\title{
ECONOMIC ANALYTICAL STUDY OF THE RISKS OF PESTICIDES RESIDUES IN TOMATO AND ORANGE CROPS
}

\author{
RASHA M. AHMED FARAG ${ }^{1}$ and MAHMOUD A. EL-SISI ${ }^{2}$
}

1. Agricultural Economics Research Institute

2. Central Laboratory of Residue analysis of Pesticides and Heavy Metals in Food, Agricultural Research Center

(Manuscript received 24 April 2018)

\begin{abstract}
$\mathrm{T}$ he research aims to study pesticide residues on tomatoes and oranges to improve and develop the management of integrated control programs, reduce economic losses and do not harm human health, To achieve this, the research relied on the results of the sample data collected from some local markets of some governorates of the Republic, Pesticide residues were evaluated and potential risks assessed for food containing pesticide residues exceeding the maximum allowable limit for each crop.

The most important results of the study:

- The results of the analysis of the sample of the study, which included 83 samples, tomatoes yield 44 samples, oranges 39 samples, showed that the number of samples free of pesticide residues 18 samples represent $21.7 \%$ of the total samples, The number of samples contaminated with pesticide residues was 65 samples representing $78.3 \%$ of the total samples. The number of samples exceeding the maximum allowable residues (MRLs) of 13 pesticides represented $20 \%$ of the total samples contaminated with pesticide residues.

- The results showed that tomato and orange crops had high pollution levels of pesticides residues. The total number of samples contaminated with pesticide residues for tomato harvest was 34 samples from 44 samples, $77.3 \%$, while 31 samples from 39 samples were estimated at 79.5 Which indicates the excessive use of pesticides on these crops.
\end{abstract}

\section{Recommendations:}

1- To tighten control on pesticides that are not allowed to be used and to track smuggled pesticides to prevent their circulation in local markets.

2- Continued pesticide residue monitoring programs in all food products to provide and update a database through which future strategies for pest control and consumer protection can be implemented through random exposure to pesticides.

3- Directing the producers of the Oranges to rationalize the use of pesticides because they use large amounts and different types of pesticides, which leads to pollution of the crop and thus causing significant economic losses. 


\title{
دراسة تحليلية اقتصادية لمخاطر متبقيات المبيدات على محصولي البرتقال و الطماطم
}

\section{رشا محمد احمد قرج" و محمود عبد السلام السيسي2}

\author{
1. - معهُ بحوث الاقتصاد الزراعي \\ 2. - الدعل المركزي لتحلبل متبقيات المبيدات والعناصر الثقبلة في الأغذية
}

\begin{abstract}
مقدمة

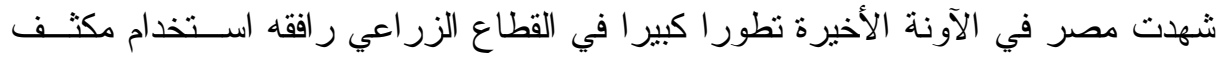

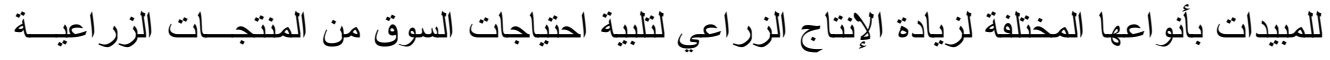

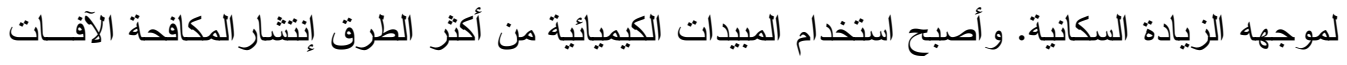

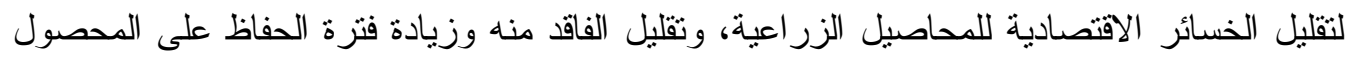
بداية من مرحلة القطف حتى المستهلك النهائى.وقد يعتقد بعض الزارعين بأن زيادة الإنتاج قد يتطلب

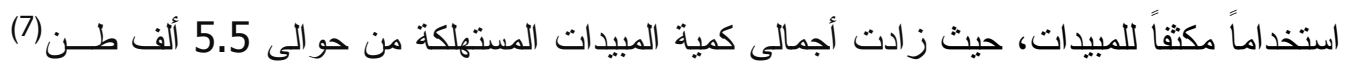

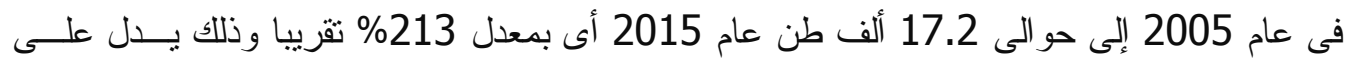
أستخدام المبيدات الزر اعية بشكل مكثف خلال العشر سنوات الأخيرة، وتبعا لكثافة هذا الاستخدام فانه ترتب عليه أضر ار للمتعاملين معها و أيضا لحيو انات المزرعة و الحشر ات النافعة لذلك لابد من توعية المز ارعين بخطر المبيدات المكثف و أرشادهم لتعليمات الأستخدام الأمن للمبيد.

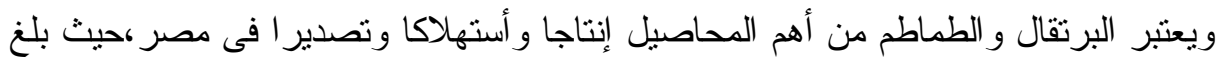

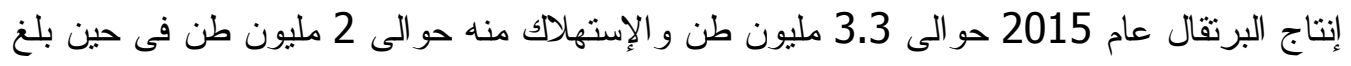

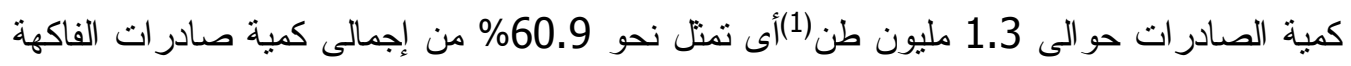

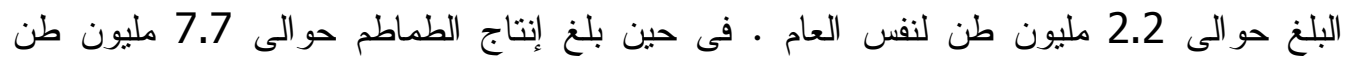
و الأستهلاك منه حو الى 7.5 مليون طن، كما بلغ كمية الصادر ات حو الى 128 ألف طن أى الى ما يعادل نحو 5\% من إجمالى كمية صادر ات الخضر البالغ حوالى 2.7 مليون طن وذللك لنفس العام.وتعتبر

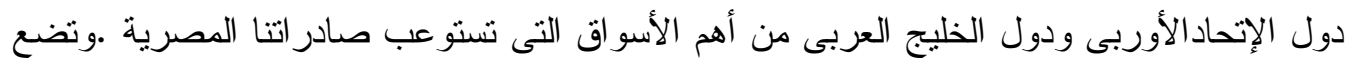

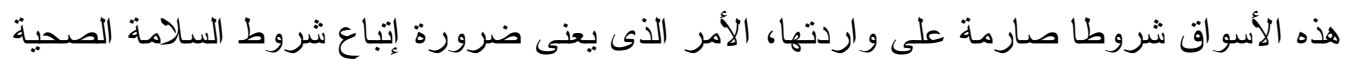

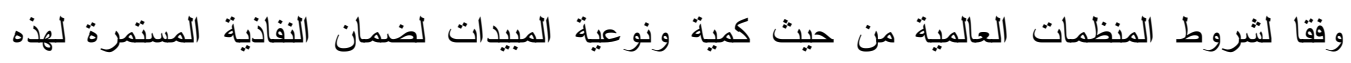
الأسواق الخارجية.

\section{مشكلة البحث}

تعتبر المحاصيل محل الدر اسة ( الطماطم و البرتقال) من المحاصيل ذات العائد الاقتصادي الكبير سواء على المستوى المحلى أو التصديرى، حيث يمثل قيمة صادرات البرتقال نحو 42.6\%

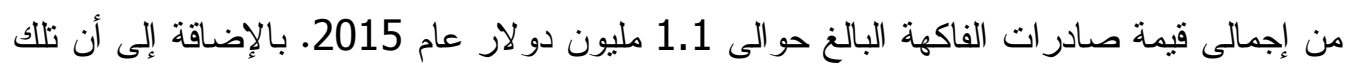


المحصولين من السلع الأكثر قبو لا لذوق المستهلك المصرى حيث يتم استهلاكهما من كل فئات المجتمع. وفى الأونة الأخيرة واجهت بعض الصادر الات المصرية الكثير من الثروط البيئية و الصحية التى تحد من كمية نفادها للأسواق الخارجية. وبالرغم من تز ايد الوعى الصحي و البيئي بخطورة

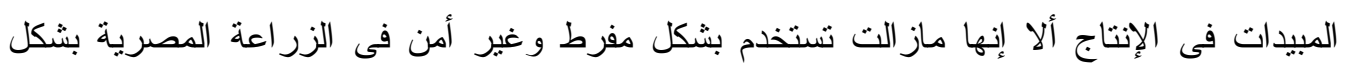
عام. ولذلك تكمن المشكلة فى قياس الإنعكاسات السلبية لأستخدامها.

\section{هدف البحث}

وفى ضوء المشكلة البحثية التي تم توضيحها يهدف البحث إلى تحليل اقتصادى لمخاطر متبقيات

المبيدات الزر اعية لمحصولى الطماطم و البرتقال. وقد إستلزم تحقيق ذلك إنجاز عدة أهداف فرعية: - - التعرف على الأهمية الأقتصادية لمحصولى الطماطم و البرنقال، و الأهمية الأقنصادية

$$
\text { للمبيدات الزر اعية المستخدمة. }
$$

- - تحليل ورصد لعينة من محصولى الدر اسة لبعض المحافظات وتقييم ما تبقى بها من متبقيات

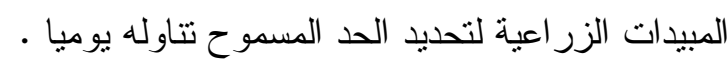

$$
\begin{aligned}
& \text { - - قياس الآثر الاقتصادي لمتنقيات المبيدات الزر اعية لمحصولي الطماطم و البرتقال. }
\end{aligned}
$$

\section{أهم النتائج في ضوء الدراسات السابقة:}

أستخلص السيسى (2014)(1) فى دراسته عن "تحليل مخاطر بعض مبيدات الآفـات الفوسـفورية العضوية في الأغذية " ان المزار عين لم يتبعوا الاحتياطات و التعليمات المناسبة فيما يتعلق باستخدام

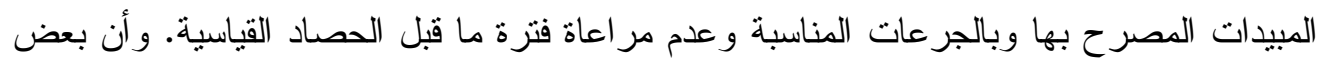
المزارعين يستخدمون المبيدات دون النظر الى موقفها من التسجيل. كما توصل جادو والخشن (2014) (2)إلى أن المبيدات المستحدثة أكثر كفاءة و أقل تلوثا للبيئة مسنـ

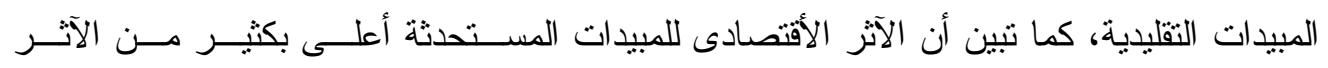

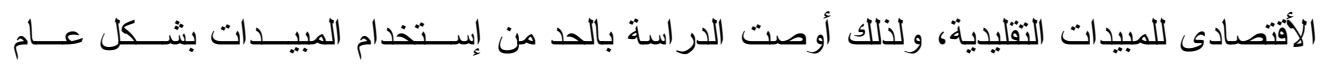
و الأتجاه إلى إستخدام المبيدات المستحدثة ولكن بالحد المسموح به وفقا للمنظمات العالمية.

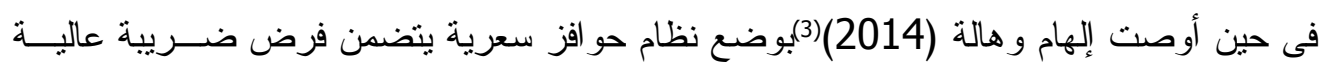

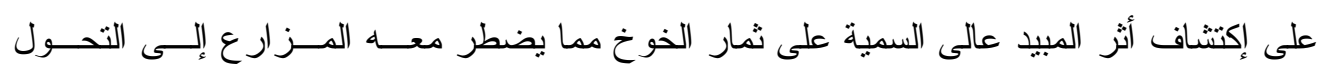
الجزئى إلى إستهلاك المبيدات منخفضة السمبة ثم التحول النهائى إلى الزر اعة النظيفة ،كما يتضمن هذا النظام منح إعانة فورية للمزارع حالة إستخدام مبيدات منخفضة السمية، وهذا من شأنه أن يقلل

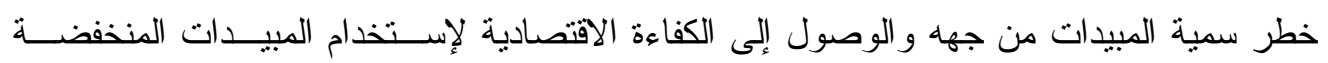

${ }^{(1)}$ Mahmoud El-sisi,"'Studies on risk analysis of some organ phosphorus pesticides in food",M.Sc Dissertation, Department of Environment and Bio-Agriculture, Faculty of Agriculture, Al-Azhar University, 2014.

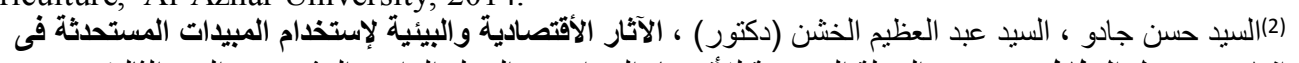

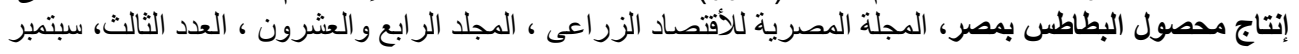

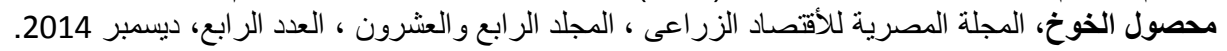


السمية من جهة أخرى. كما أوصت بضرورة إجر اء العمليات الزر اعيــة فـى مو اعيــــها لتهيئـــة ظروف غير مواتية لنمو الحشرة.

كما أثشار سهرة ومحمد نور الدين (2016)(4) أن نطبيق نظام المكافحة المتكاملة له أثار اقتصادية

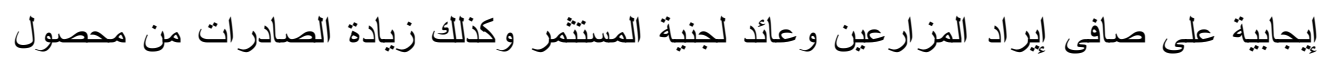

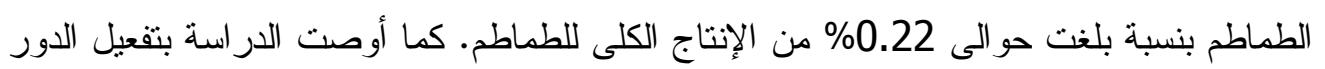
الأرشادى لكى يقوم بتوعية وتدريب الزراع على إستخدام برنامج المكافحة المتكاملة.

\section{الطريقة البحثية ومصادر البيانات}

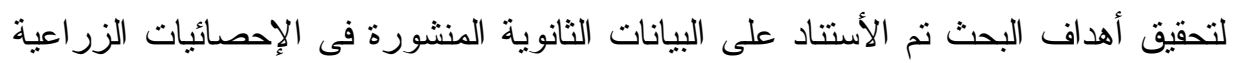

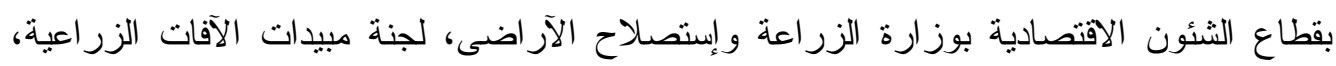

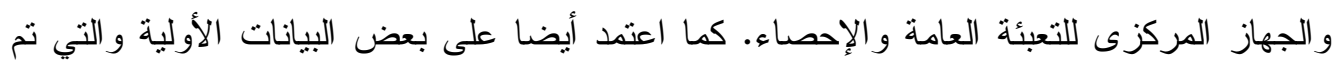
جمعها من بعض أسواق الجملة لبعض محافظات الجمهورية بواسطة المعمل المركزى لتحليل

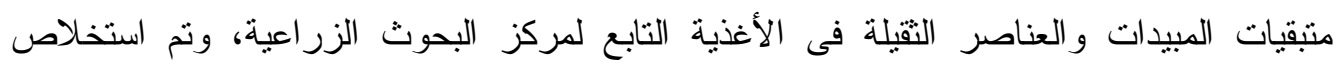

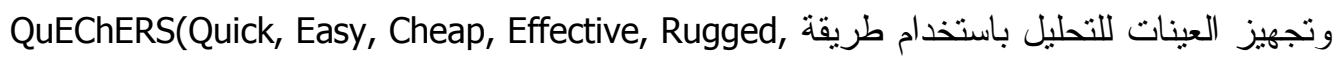
(9) and Safe)

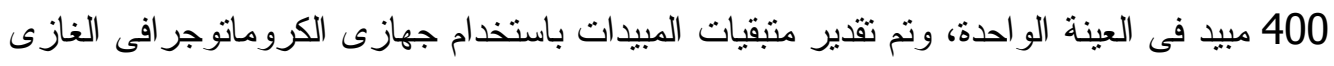
المزود بمطياف الكتلة المنتالى(GC-MS/MS) و الكروماتوجرافى السائل المزود بمطياف الكتلة المتتالى(LC-MS/MS) .ونم أيضاً تقييم المخاطر المحتملة التى قد تتتج عن تتاول الاغذية التى تحتوى ولئي على متبقيات مبيدات اكبر من الحد الأقصى المسموح به لكل محصول.

كما أستتد البحث علي أساليب التحليل الإحصائي من الناحيتين الوصفية والكمية، كاستخدام الأساليب الإحصائية البسيطة منل النسب المئوية والمتوسطات الحسابية، إلى جانب استخدام النموذج الأنحدار الخطى البسيط لنقدير معدلات النمو السنوية للمتغيرات الاقتصادية. نتائج الار اسة ومناقشتها

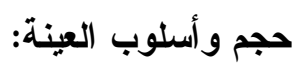

يقوم المعمل المركزي لتحليل متنقيات المبيدات و العناصر الثقبلة في الأغذية بقياس ثلــوث

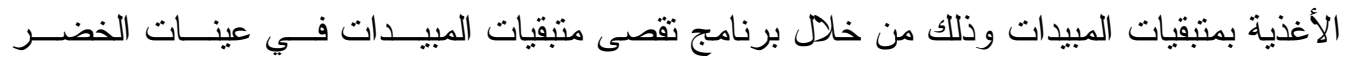

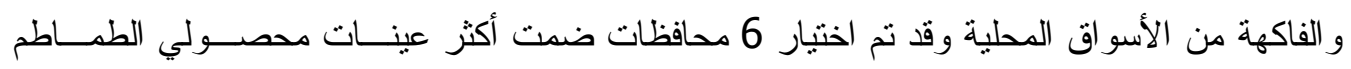

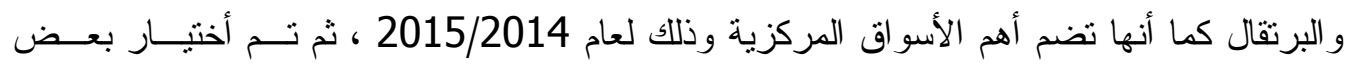

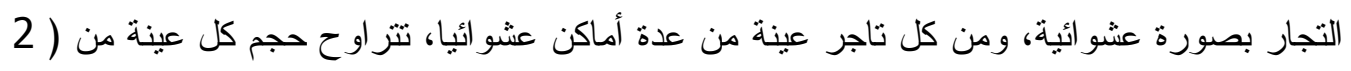

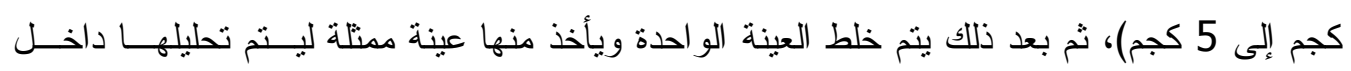
المعمل. وكان إجمالي عدد عينات لكلا المحصولين نحو 83 عينة نم توزيعها : كما يلـــي: القــاهرة

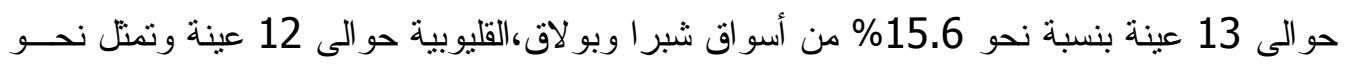

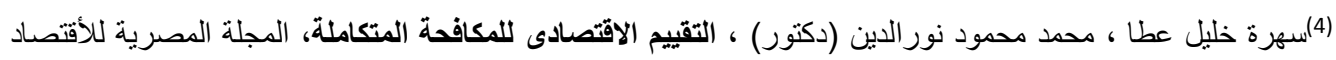
الزراعى، الدجلد السادس و العشرون، العدد الثانى، يونيو 2016. 
14.4\% من سوق العبور ، البحيرة حو الى 17 عينة بنسبة نحو 20.4\% مـــن منطقــة النوباريــة،

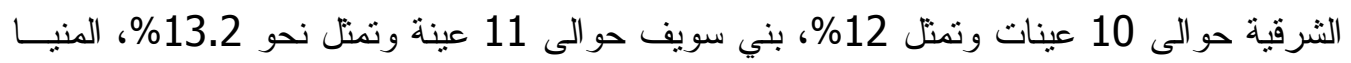

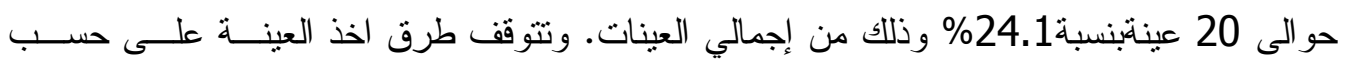

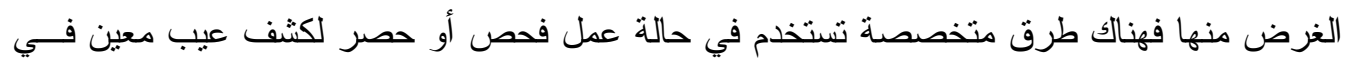

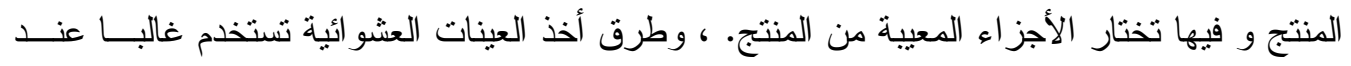

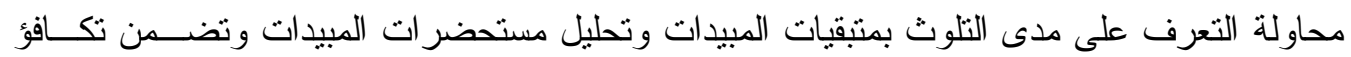
فرص الاختيار لكل مكان حيث تؤخذ العينة المركبة من أماكن متعددة تخلط معا ويؤخذ منهــــا عينــة ممنلة. الإطار النظرى والتحليلى للبحث

بعض المصطلحات والتعريفات الهامة(17): تعريف مبيدات الآفات الزر اعية:

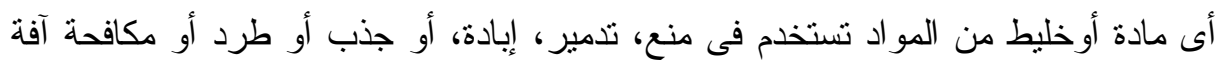

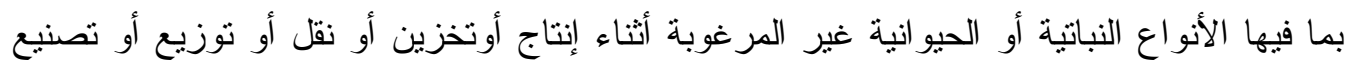

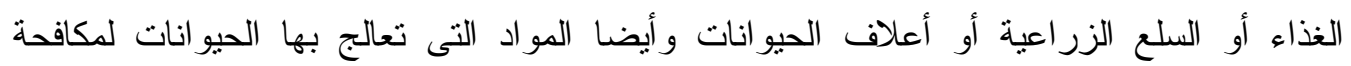

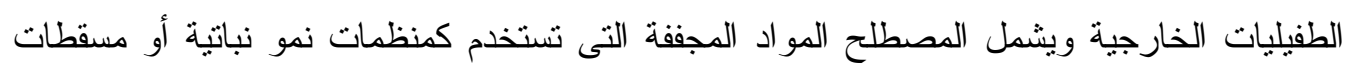

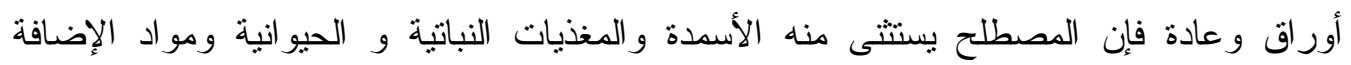
للأغذية و الأدوية البيطرية. Pesticide Residues : متبقيات المبيدات الادوبة لمعندات يقصد بها أى أثر لمادة معينة بالغذاء أو السلع الزراعية أو أعلاف الحيو انات ناتجة من

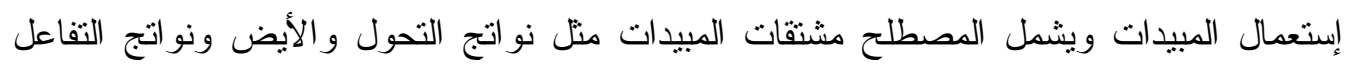
و الثنوائب التى تعنبر ذات أهمية سمية وأيضا فإن المصطلح يشمل المتبقيات غير معلومة المصادر أو النى لا يمكن تجنبها.

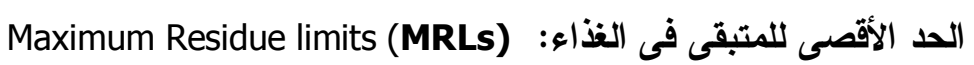

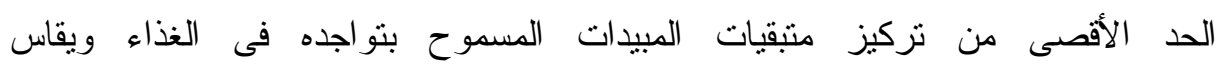

$$
\text { بالمبل المقبول ام/كجم. }
$$

يقصد بها كمية متبقيات المبيدات التى ينتاولها الفرد يومياً من جراء نتاوله لأغذية ملوثة

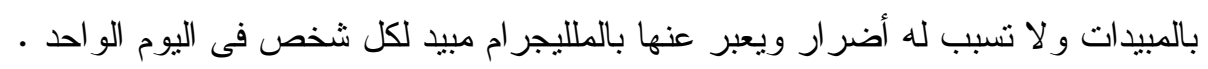

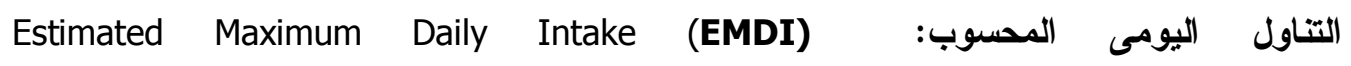
يقصد بها حساب كمية متنقيات المبيدات النى يتتاولها الفرد يومياً من جراء تتاوله أغذية ملوثة

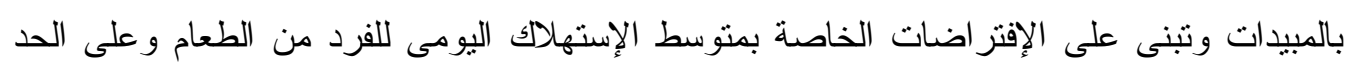

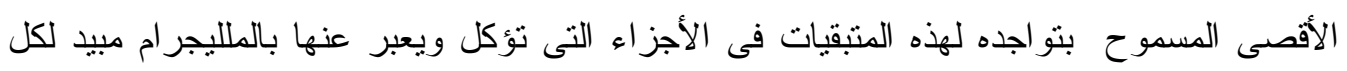




\section{الأهمية الاقتصادية لمحصولى البحث :}

تشير البيانات الواردة بجدول (1) المتغير ات المختلفة لمحصولى الطماطم والبرتقال خلد الفترة (20052015) ،ومنها ينتين ما يلى:

\section{أولا : محصول الطماطم}

بلغت المساحة المزروعة بالطماطم على مستوى الجمهورية خــلدل متوســــــــرة الدراســة (2005-2015)حو الى 521 ألف فدان ، قدر إنتاجها بحو الى 8.592 مليون طن .كما يتبين مــن نفسـس الجدول أن هنالك إنخفاض فى إنتاج الطماطم فى مصر، ويرجع هذا النتاقص إلى إنخفاض الرقعة المزروعة بها حيث بلغا حو الى 495.4 ألف فدان، 8.391 مليون طن عام 2005، فى حين بلغا حوالى 468 ألف فدان، 7.727مليون طن عام 2015، بمعدل تتاقص قدر بنحو 5\%، 8. 8.

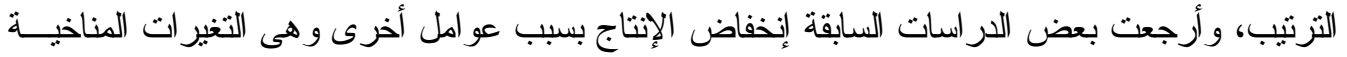

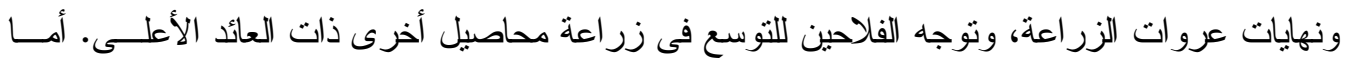
بالنسبة للإنتاجية الفدانية فقد تذبذبت بين الارتفاع و الانخفاض الطفيف من عام لآخر طو ال فترة الدر اسة، إذ إذه

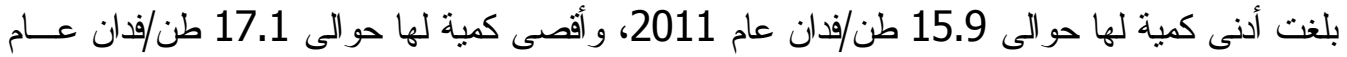

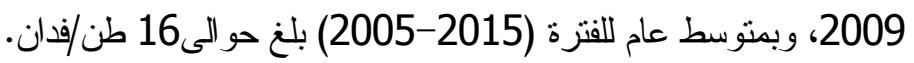
ويعد محصول الطماطم من أهم محاصيل الخضر التى تلعب دورا رئيسيا فــى دعــم النثــاط الاقتصادى للدولة، حيث أنه تتو افر لديها المقومات لزيادة صادر اتها للأسو اق الخارجية ـ ـوتشير بيانات

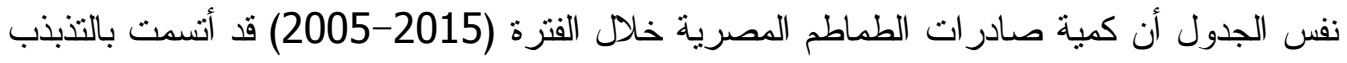
حيث بلغت حو الى 18 ألف طن عام 2005 بقيمة تصديرية بلغت حو الى 4 مليون دو لار و انخفضت

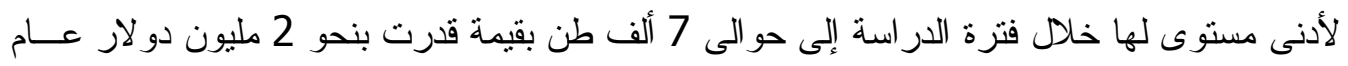

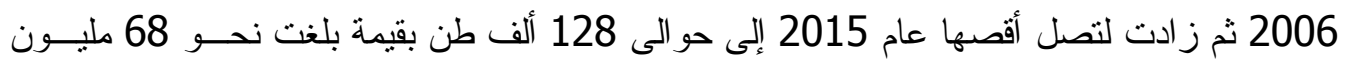

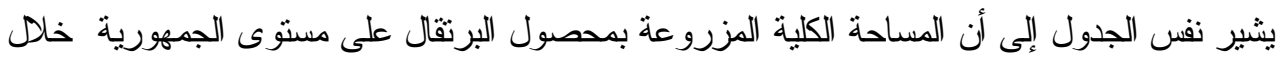

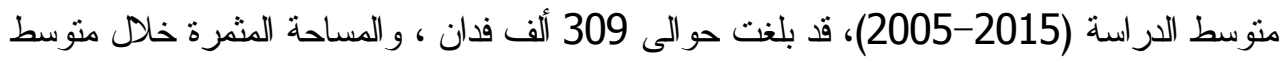
نفس الفترة حو الى 253 ألف فدان ، قدر إنتاجها بحو الى لى 2.521 مليون طن .كما ينتين أن هنآك اتجاه

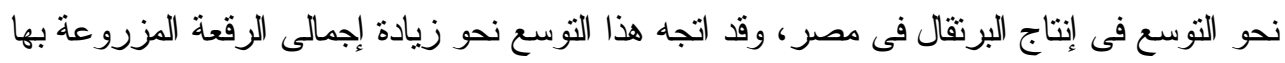

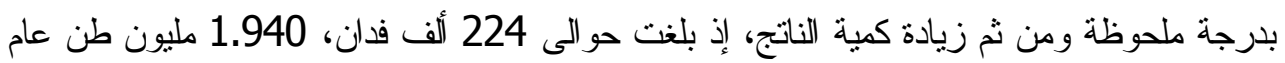

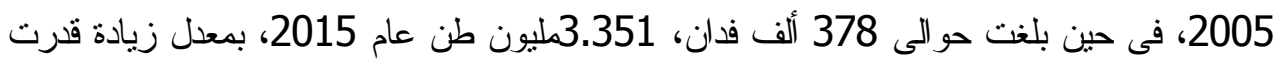
نحو 68\%، 73\% لكل من المساحة الكلية والإنتاج على الترنيب. أما بالنسبة للإنتاجية الفدانية فقد تذبذبت بين الارتقاع والانخفاض الطفيف من عام لآخر طوال فترة الدراسة، إذ بلغت أدنى كمية لها

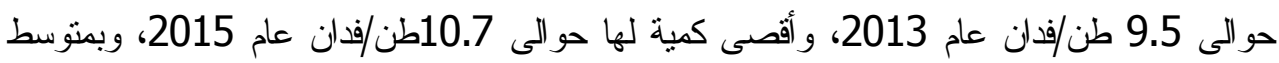

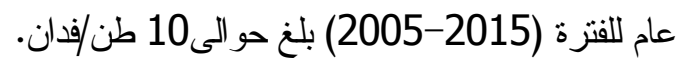


وتتثير بيانات نفس الجدول أن كمية صادرات البرتقال المصري خلد الفترة (20052015) قد أنسمت بالزيادة حيث بلغت حوالى 214 ألف طن عام 2005 بقيمة تصديرية بلغت

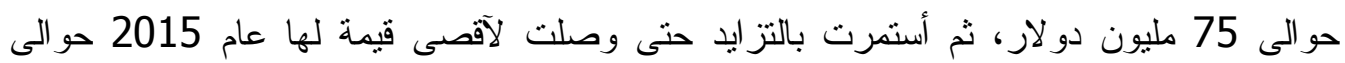
1353 ألف طن بقيمة تصديرية بلغت حو الى 464 مليون دو لار . جدول رقم (1) تطور بعض المتغيرات الإنتاجية والاقتصادية لمحصول الطماطم والبرتقال خلال الفترة (2015-2005)

\begin{tabular}{|c|c|c|c|c|c|c|c|c|c|c|c|}
\hline \multicolumn{6}{|c|}{ البرتقال } & \multicolumn{5}{|c|}{ الطماطم } & \multirow[b]{2}{*}{ السنوات } \\
\hline مليدة & كمية ألف طادرات & (ألف طن) & (طنافنان) & المساحة & ألفاحة & مليمة & ألف كية & (الفن طن) & (طنالفان) & (ألف & \\
\hline 75 & 214 & 1940 & 9.6 & 201 & 224 & 4 & 18 & 8391 & 16.9 & 495 & 2005 \\
\hline 65 & 283 & 2120 & 10.1 & 209 & 236 & 2 & 7 & 8576 & 16.4 & 524 & 2006 \\
\hline 98 & 271 & 2055 & 9.7 & 213 & 249 & 4 & 20 & 8639 & 16.1 & 537 & 2007 \\
\hline 382 & 638 & 2138 & 9.6 & 222 & 262 & 9 & 23 & 9204 & 16.1 & 572 & 2008 \\
\hline 495 & 822 & 2372 & 10.1 & 235 & 296 & 20 & 24 & 10279 & 17.1 & 600 & 2009 \\
\hline 491 & 821 & 2401 & 10.0 & 241 & 314 & 26 & 40 & 8545 & 16.6 & 515 & 2010 \\
\hline 538 & 1042 & 2578 & 9.8 & 263 & 334 & 19 & 62 & 8054 & 15.9 & 506 & 2011 \\
\hline 454 & 1322 & 2786 & 9.9 & 283 & 356 & 29 & 29 & 8571 & 16.6 & 515 & 2012 \\
\hline 491 & 1108 & 2855 & 9.5 & 299 & 375 & 60 & 81 & 8269 & 16.9 & 489 & 2013 \\
\hline 473 & 877 & 3136 & 10.4 & 301 & 370 & 72 & 82 & 8265 & 16.2 & 510 & 2014 \\
\hline 464 & 1353 & 3351 & 10.7 & 313 & 378 & 68 & 128 & 7727 & 16.5 & 469 & 2015 \\
\hline 366 & 796 & 2521 & 10.0 & 253 & 309 & 28 & 47 & 8593 & 16.5 & 521 & المتوسط \\
\hline
\end{tabular}

1- وزارة الزراعة واستصلاح الأراضي -قطاع الشئون الاقتصادية -الإدارة المركزية للاقتصاد الزراعي والإحصاء- نشرة الاقتصاد

$$
\text { الزر اعي - أعداد متفرقة. }
$$

2- الجهاز المركزي للتعبئة العامة والإحصاء، شبكة مركز المعلومات (WWW.capmas.gov.eg).

\section{الأهمية الاقتصادية للمبيدات الزراعية}

تعتبر الآفة الزر اعية من ضدن العوائق التى نوجهه مزارعى محصولى الدراســـة وتعـــوق

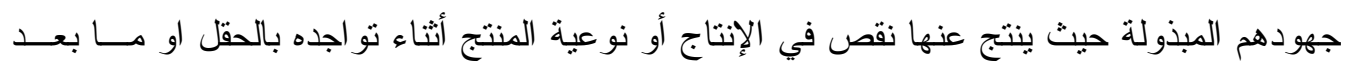

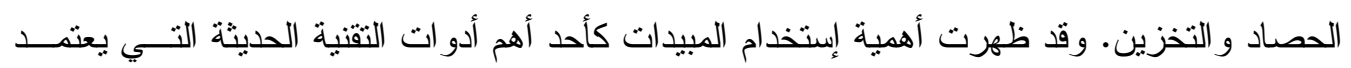

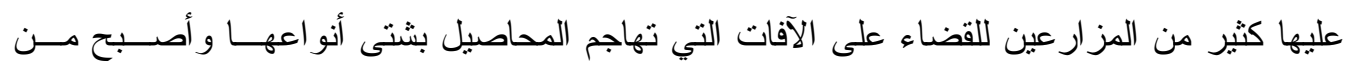

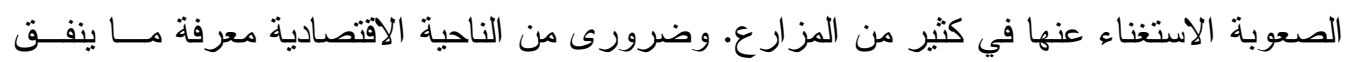

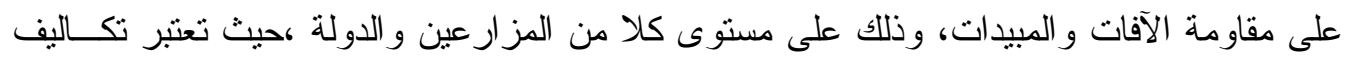

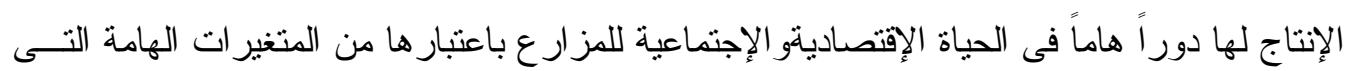


تؤثز بشكل مباشر على دخله ومستوى معيشته وتعتبر الموجه الأساسى لإستخدام الموارد الزراعيــة

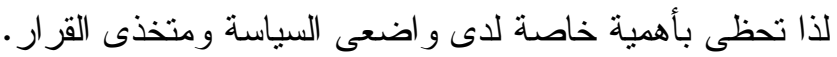

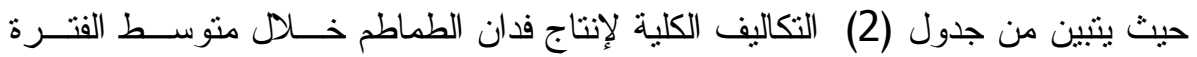
(2011-2015) و التي بلغت حو الى 4937 جنية /فدان وذللك كمتوسط للعرو ات الثثلاثة، فى حسين قدرت تكاليف مقاومة الآفات بحو الى 376 جنية/فدان تمنتل نحو 7.6\% مــن إجمــالى التكــاليف ، وقدرت قيمة المبيدات المستخدمة حو الى 233 جنية /فدان، منلت نحو 4.7\% من التكاليف الكلية . ونظر العدم توفر بيانات عن تكاليف إنتاج البرتقال، وبمعلومية أن محصول البرتقال يمتل نحو 72\% من إجمالى إنتاج المو الح فى مصر، فقد أعتبر البحث أن تكاليف الموالح ممنلـــة لتكــاليف البرتقـــال إستتادا على كثبر من الدراسات الميدانية لمحصول البرثقال وتبين أن تكاليفه تقترب كثثر ا من تكاليف

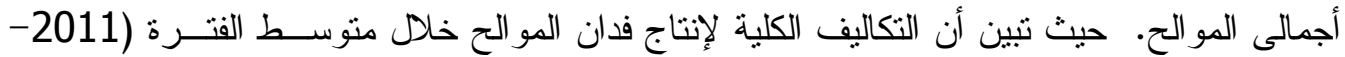

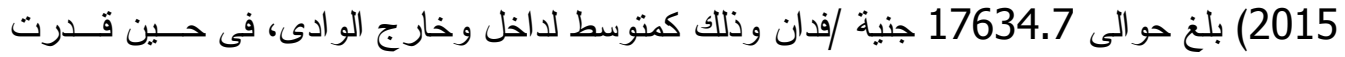
تكاليف مكافحة الآفات بحو الى 1769.7 جنبة/فدان تمنل نحو 10\% من إجمالى التكاليف ، وقــدرت قيمة المبيدات المستخدمة حو الى 1203.7 جنية /فدان بنسبة بلغت نحو 6.8\% من التكاليف الكلية . جدول (2) التكاليف الكلية وتكاليف مقاومة الآفات وسعر المبيدات لمحصولى الطماطم و الموالح خلال القترة (2015-2011)

\begin{tabular}{|c|c|c|c|c|c|c|c|c|c|c|c|c|c|c|c|}
\hline \multicolumn{5}{|c|}{ سبو البيان } & \multicolumn{5}{|c|}{ 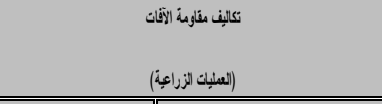 } & \multicolumn{5}{|c|}{ الناليف الكلة (بإبإيلز) } & \\
\hline \multicolumn{2}{|c|}{ السوالح } & \multicolumn{3}{|c|}{ الططيم } & \multicolumn{2}{|c|}{ البوالع } & \multicolumn{3}{|c|}{ الثطاطم } & \multicolumn{2}{|c|}{ السوليح } & \multicolumn{3}{|c|}{ الثططم } & \\
\hline لازي & الثولى للز & التيلى & الصبلى & الشتوى & الوارج & 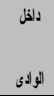 & الثنلي & الصيانى & الثنّى & 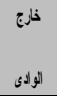 & الفن الوائ. & النئى & 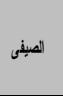 & الثنّى & \\
\hline 1560 & 874 & 219 & 196 & 181 & 2200 & 1164 & 308 & 347 & 297 & 15723 & 13784 & 3805 & 4632 & 4499 & 2011 \\
\hline 1250 & 1205 & 270 & 198 & 191 & 1890 & 1495 & 353 & 356 & 298 & 17418 & 16290 & 3974 & 4861 & 4817 & 2012 \\
\hline 1250 & 990 & 288 & 215 & 208 & 1900 & 1470 & 397 & 389 & 334 & 19547 & 18803 & 4594 & 5060 & 5006 & 2013 \\
\hline 1350 & 990 & 287 & 259 & 207 & 2300 & 1470 & 437 & 415 & 337 & 19746 & 17238 & 4995 & 5525 & 5370 & 2014 \\
\hline 1350 & 1218 & 308 & 252 & 218 & 2050 & 1758 & 468 & 476 & 428 & 19636 & 18162 & 5169 & 5885 & 5867 & 2015 \\
\hline 1352 & 1055.4 & 274.4 & 224 & 201 & 2068 & 1471.4 & 392.6 & 396.6 & 338.8 & 18414 & 16855.4 & 4507.4 & 5192.6 & 5111.8 & التربط \\
\hline
\end{tabular}

المصدر : وزارة الزر اعة واستصلاح الأر اضي -قطاع الشئون الاقتصادية -الإدارة المركزية للاقتصاد الزر اعي و الإحصاء- نشرة الاقتصاد الزر اعي-

مما لا شك فيه أن أسعار مستلزمات الإنتاج الزراعى المستوردة تؤثز بشكل مباثر على

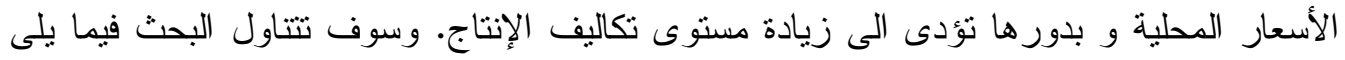

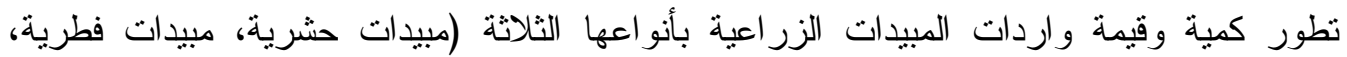
مبيدات حشائش)، ومعرفة ما ينفق عليها من عملة صعبة لاستير ادها سنويا. 
وباستعر اض بيانات الجدول رقم (3) لكمية وقيمة الواردات المصرية لدختلف المبيدات

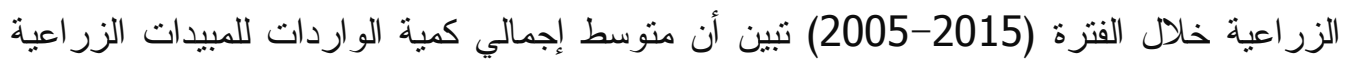
بلغ حو الى11.2 ألف طن، بقيمة بلغت حو الى 93.8 مليون دو لار وقد بلغ منتوسط واردات الفيط المبيدات الحشرية حو الى 4.3 ألف طن بما بعادل نحو 38.4\% من إجمالي كمية و اردات المبيدات الزر اعبة،

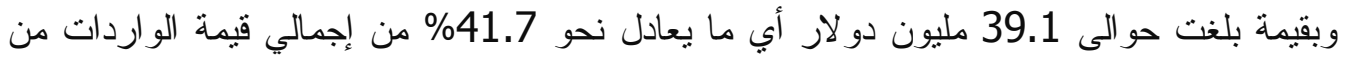

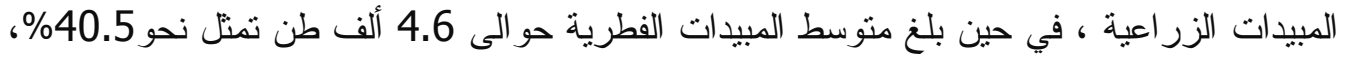
بقيمة بلغت حوالى 34.4 مليون دولار بما بعادل 36.7\% من إجمالي قيمة واردات المبيدات

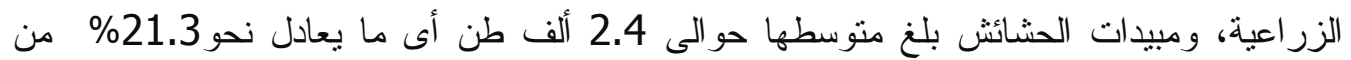

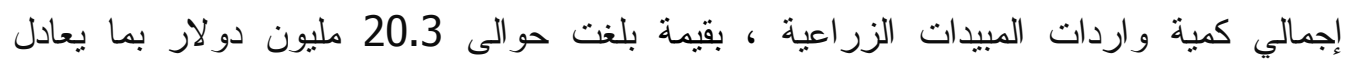
21.6 من إجمالي قيمة واردات المبيدات الزر اعية. ومن المعادلة رقم (1) بالجدول (4) التضح أن إجمالى كمية الواردات من المبة المبيدات الحشرية

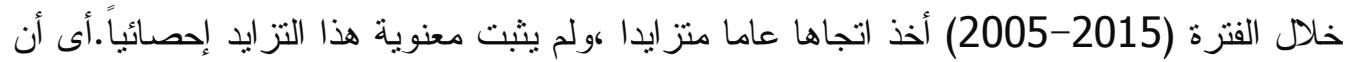
كمية واردات المبيدات الحشرية تتقلب حول متوسطها و المقدر بحوالى 4.3 ألف طن خلال فترة

ومن المعادلة رقم (2) تبين أن إجمالى كمية الواردات من المبيدات الفطرية أخذ اتجاها عاما

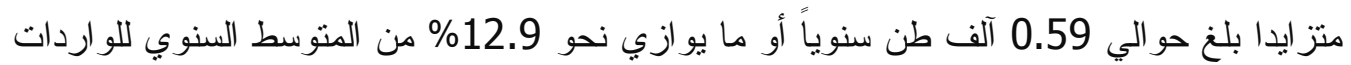

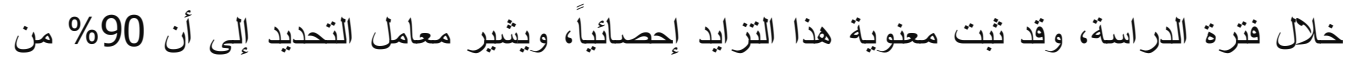

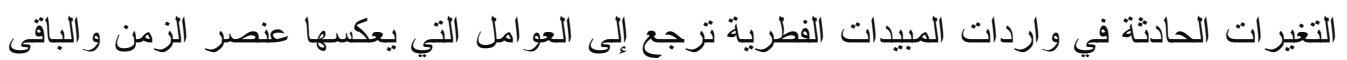
يرجع إلى عو امل غير مقيسة. ومن المعادلة رقم (3) اتضح أن إجمالى كمية الواردات من المبيدات الحشائش أخذت اتجاها

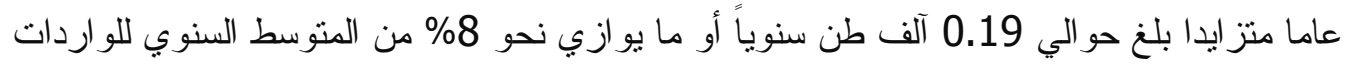
خلال فترة الدراسة، وقد ثبت معنوية هذالتز ايد إحصائياً، ويشير معامل التحديد إلى أن

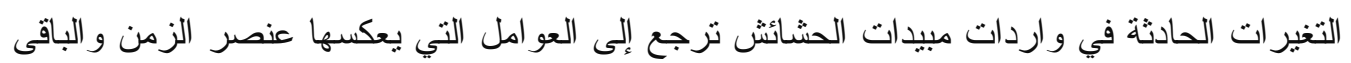
يرجع إلى عو امل غير مقيسة.

جدول رقم (3) كمية وقيمة الواردات المصرية من مختلف المبيدات الزراعية

خلال الفترة (2015-2005)

\begin{tabular}{|c|c|c|c|c|c|c|c|c|}
\hline \multicolumn{2}{|c|}{ إجمالي } & \multicolumn{3}{|c|}{ قيمة الواردات (مليون دولار) } & \multicolumn{3}{|c|}{ كمية الواردات (بالأف طن) } & \multirow{2}{*}{ ال السنوات } \\
\hline القيمة & الكمية & الحشائش & الفطرية & الحشرية & الحشائش & الفطرية & الحشرية & \\
\hline 27.4 & 5.5 & 5.6 & 5.6 & 16.2 & 0.9 & $\overline{\mid 1.1}$ & 3.5 & 2005 \\
\hline 65.1 & 9.8 & $\overline{|c|}$ & 21.8 & 32.5 & $\overline{|c| 8}$ & 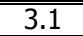 & $4 \overline{4.9}$ & 2006 \\
\hline \begin{tabular}{|c|}
74.6 \\
\end{tabular} & 9.1 & $\overline{9.9}$ & 23.6 & $\overline{441.1}$ & 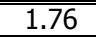 & 2.6 & 4 & 2007 \\
\hline 70.6 & 9.5 & 15.9 & 20.9 & 33.8 & 2.1 & 3.9 & 3.6 & 2008 \\
\hline 79.9 & 9.0 & 20.2 & 23.6 & 36.1 & 2.5 & 3.2 & 3.3 & 2009 \\
\hline 122.5 & $\begin{array}{l}11.6 \\
\end{array}$ & 43.3 & 35.9 & 433.4 & 2.9 & 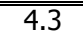 & 4.4 & 2010 \\
\hline 120.9 & $\begin{array}{l}12.9 \\
\end{array}$ & $\overline{18.2}$ & 477.0 & 55.8 & 2.5 & 5.3 & 5.1 & 2011 \\
\hline 125.0 & $\begin{array}{l}14.0 \\
\end{array}$ & 24.6 & 244.7 & 55.7 & 2.8 & (6.4 & 4.8 & 2012 \\
\hline 106.9 & $\begin{array}{l}13.7 \\
\end{array}$ & 24.5 & 422.3 & 40.1 & 3.5 & 5.9 & 4.2 & 2013 \\
\hline 100.7 & 111.4 & 19.7 & 488.9 & 32.0 & 2.3 & 6.0 & 3.1 & 2014 \\
\hline 138.1 & $\bar{~} 17.2$ & $\overline{30.3}$ & 864.1 & 4 & $\bar{~} 3.4$ & 8.3 & "5.5 & 2015 \\
\hline $\begin{array}{l}93.8 \\
\end{array}$ & 111.2 & 20.3 & 34.4 & 39.1 & 2.4 & 4.6 & 4.3 & المتوسط \\
\hline
\end{tabular}

المصدر: وزارة الزراعة واستصلاح الأراضي -قاءعاع الثئون الاقتصادية -الإدارة المركزية للاقتصاد الزراعي 
جدول رقم (4) معادلات الاتجاه الزمني العام لتطور واردات المبيدات الزراعية لمصر

خلا الفترة (2015-2005)

\begin{tabular}{|c|c|c|c|c|c|c|c|}
\hline 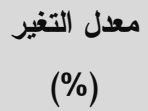 & $\mathbf{F}$ & $\mathbf{R}^{2}$ & b & A & البيان & & رقمث \\
\hline 1.18 & 0.40 & 0.04 & $\begin{array}{c}0.05 \\
(0.63)\end{array}$ & 3.9 & الحشبيدات & \multirow{3}{*}{ 可 } & 1 \\
\hline 12.9 & 83.6 & 0.90 & $\begin{array}{l}0.59 \\
(9.1)\end{array}$ & 1 & الفطبيدات & & 2 \\
\hline 8 & 20.9 & 0.69 & $\begin{array}{l}0.19 \\
(4.6)\end{array}$ & 1.24 & المشياتش & & 3 \\
\hline 4.5 & 3.5 & 0.28 & $\begin{array}{c}1.8 \\
(1.9)\end{array}$ & 28.5 & الحشبيدات & \multirow{3}{*}{ 哥 } & 4 \\
\hline 13.9 & 78.4 & 0.89 & $\begin{array}{c}4.8 \\
(8.9)\end{array}$ & 5.6 & الفبريدات & & 5 \\
\hline 9.8 & 5.8 & 0.39 & $\begin{array}{c}2 \\
(2.4)\end{array}$ & 8.3 & المبيدات & & 6 \\
\hline
\end{tabular}

T = تثير إلي قيمة (t) الدحسوبة

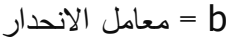

a

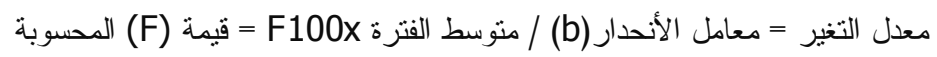

=R معامل التحديد $=R^{2}$

المصدر: حسبت من الجدول رقم (3).

ومن المعادلة رقم (4) تبين أن قيمة الواردات من المبيدات الحشرية خلال الفترة (2005-

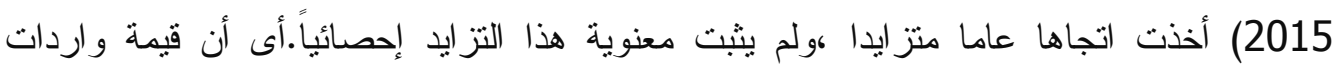

المبيدات الحشرية تتقلب حول منوسطها و المقدر بحو الى 39.1 مليون دو لار خلال فترة الدراسة. ومن المعادلة رقم (5) بنفس الجدول اتضح أن قيمة الواردات من المبيدات الفطرية أخذت

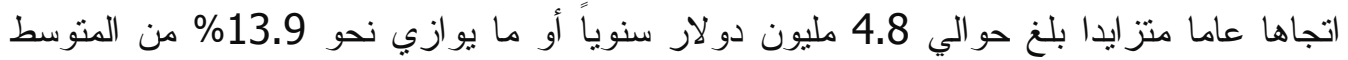
السنوي لقيمة الواردات خلال فترة الدراسة، وقد ثتتت معنوية هذالتز ايد إحصائياً، ويشير معامل التحديد إلى أن 89\% من التغيرات الحادثة في قيمة واردات المبيدات الفطرية ترجع إلى العوامل التي يعكسها عنصر الزمن و الباقى يرجع إلى عو امل غير مقيسة.

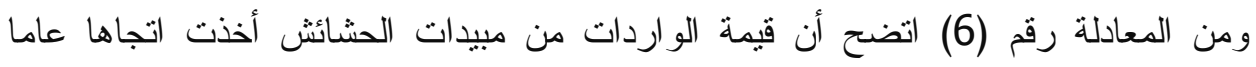

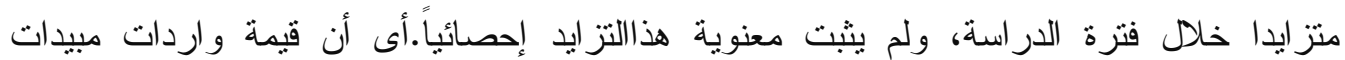
الحشائش تتقلب حول متوسطها و المقدر بحو الى 20.3 مليون دو لار خلال فترة الدر اسة. 


\section{نتائج تحليل متبقيات المبيدات:}

يشير جدول (5) إلى توصيف العينة التى تم جمعها من بعض أسواق الجملة لبعض

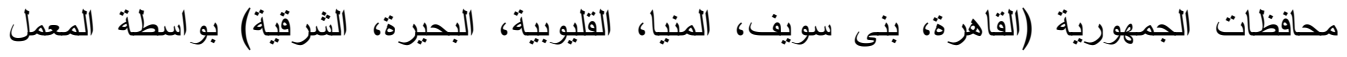

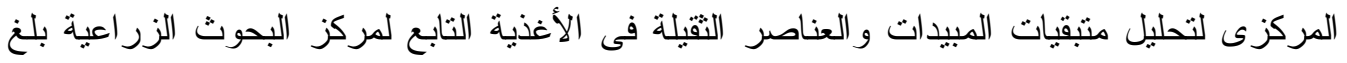
حجمها 83 عينة. حيث كانت عدد عينات محصول الطماطم 44، البرتقال 39 عينة. وأستنتج أن عدد العينات الخالية من متنقيات المبيدات 18 عينة تمثل نحو 21.7\% من إجمالى العينات، وبلغ عدد العينات الملوثة بمتققيات المبيدات 65 عينة تمثل نحو 78.3\% من إجمالى العينات، وكان عدد العينات التى تخطت الحد الأقصى المسموح به من منتقيات المبيد 13 عينة بنسبة نحو 20\% من دهن

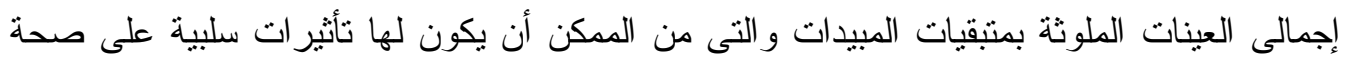

\section{1- نتائج محافظات عينة الارسة لمحصولين (الطماطم، البرتقال):}

يتبين من نتائج الدراسة بنفس الجدول أن92.3 نحو \% من إجمالى عينات محافظة القاهرة كانت ملوثة بمتبقيات المبيدات، وأن نحو 8.3\% من إجمالي العينات الملوثة قد احتوت على عنى منتقيات مبيدات أعلى من الحد الأقصى المسموح به، والنى من المككن أن يكون لها تأثيرات سلبية على دهى صحة المستهلكين، في حين أن نحو 7.7\% فقط من إجمالي عينات هذه المحافظة كانت خالية نماماً من منتقيات المبيدات. كذلك أوضحت نتائج الدر اسة احتو اء عينات نفس المحافظة على نحو 21.1 من إجمالي المبيدات التي أظهرتها نتائج الدراسة لإجمالي العينات منها نحو 2.1\% أعلى من الحد الأقصى المسموح به.

كما يوضح نفس الجدول أن نحو75\% من إجمالى عينات محافظة القليوبية كانت ملوثة بمتبقيات المبيدات، وأن نحو 11.1\% من إجمالي العينات الملوثة قد احتوت على متبقيات مبيدات

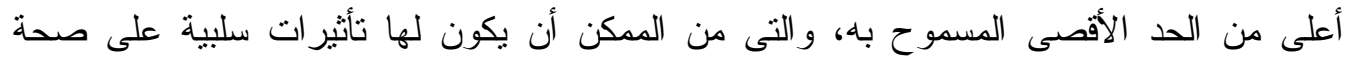
المستهلكين، في حين أن نحو 25\% من إجمالي عينات هذه المحافظة كانت خالية تماماً من منتقيات

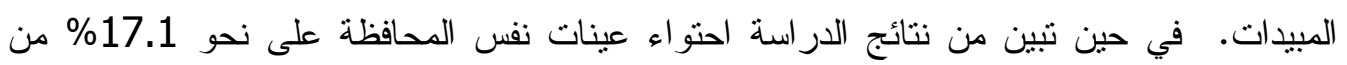

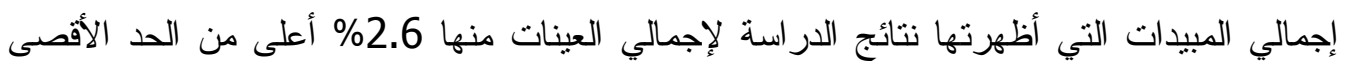

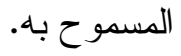

كذللك يتضح من نفس الجدول أن نحو 82.4\% من إجمالى عينات محافظة البحيرة كانت ملوثة بمتبقيات المبيدات، وأن نحو 28.6\% من إجمالي العينات الملوثة قد احتوت على متنقيات

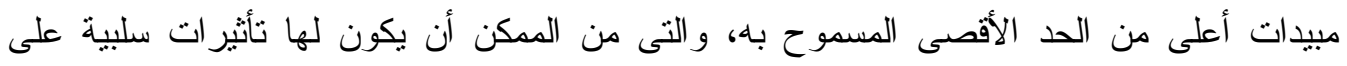
صحة المستهلكين، في حين أن نحو 17.6\% من إجمالي عينات هذه المحافظة كانت خالية تماماً من

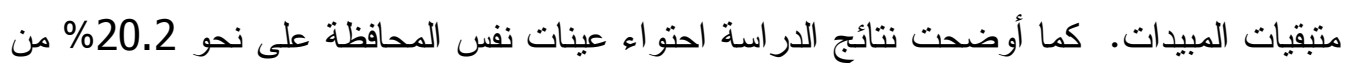
إجمالي المبيدات التي أظهرتها نتائج الدر اسة لإجمالي العينات منها نحو 8.7 أعلى من الحد الأقصى

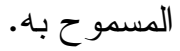


كما يوضح نفس الجدول أن 100\% من إجمالى عينات محافظة الثرقية كانت ملوثة بمنبقيات المبيدات، وأن نحو 30\% من إجمالي العينات الملوثة قد احتوت على ملى منقيات مبيدات أعلى أعلى

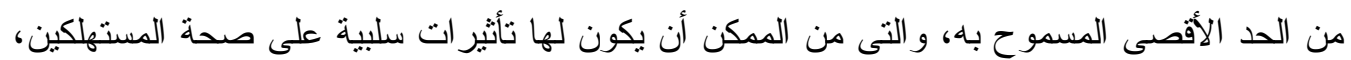
كما أنه لا يوجد أب عينات خالية من متبقيات المبيدات بهذه المحافظة. في حين تنين من نتائج الدراسة احتو اء عينات نفس المحافظة على نحو 18.9\% من إجمالي المبيدات التي أظهرتها نتائج الدر اسة لإجمالي العينات منها نحو 9.3\% أعلى من الحد الأقصى المسموح به.

جدول (5) نسب التلوث بمحافظات عينة الدراسة لمحصولى الطماطم والبرتقال

لموسم 2015/2014

\begin{tabular}{|c|c|c|c|c|c|c|c|c|c|c|c|}
\hline \multicolumn{2}{|c|}{ العبيدات المتخطية } & \multicolumn{2}{|c|}{$\begin{array}{c}\text { إجمالي المبيدات } \\
\text { (228 }\end{array}$} & \multicolumn{2}{|c|}{ العينات المتخطية } & \multicolumn{2}{|c|}{ العينات الملوثة } & \multicolumn{2}{|c|}{ العينات الخالية } & \multirow{2}{*}{$\begin{array}{c}\text { علد العينات (ن3) } \\
\text { (83) }\end{array}$} & \multirow{2}{*}{ المحافظ } \\
\hline$\%$ & العد & $\%$ & العدد & $\%$ & العد & $\%$ & العد & $\%$ & العد & & \\
\hline 2.1 & 1 & 21.1 & 48 & 8.3 & 1 & 92.3 & 12 & 7.7 & 1 & 13 & القاهرة \\
\hline 2.6 & 1 & 17.1 & 39 & 11.1 & 1 & 75.0 & 9 & 25.0 & 3 & 12 & القليوبية \\
\hline 8.7 & 4 & 20.2 & 46 & 28.6 & 4 & 82.4 & 14 & 17.6 & 3 & 17 & البحيرة \\
\hline 9.3 & 4 & 18.9 & 43 & 30.0 & 3 & 100.0 & 10 & 0.0 & 0 & 10 & الشرقية \\
\hline 6.3 & 1 & 7.0 & 16 & 14.3 & 1 & 63.6 & 7 & 36.4 & 4 & 11 & سويفى \\
\hline 8.3 & 3 & 15.8 & 36 & 23.1 & 3 & 65.0 & 13 & 35.0 & 7 & 20 & المنيا \\
\hline & 14 & & $\begin{array}{c}22 \\
8\end{array}$ & & 13 & & 65 & & 18 & 83 & الإجمالى \\
\hline
\end{tabular}

المصدر : جمعت وحسبت من بيانات عينة الدر اسة.

أما محافظة المنيا فقد أظهرت نتائج التحليل بذات الجدول أن نحو 65\% من إجمالى عبناتها

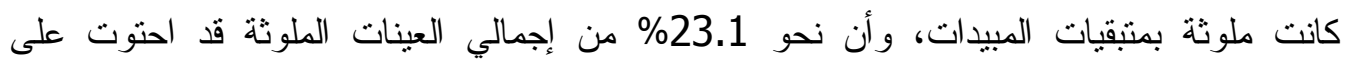
متبقيات مبيدات أعلى من الحد الأقصى المسموح بها، كما أن نحو 35\% من بن إجمالي عينات هذه

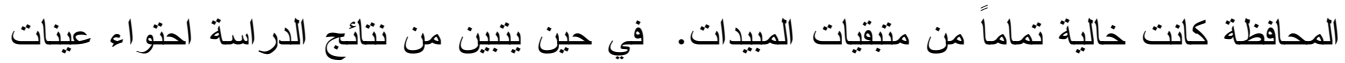
نفس المحافظة على نحو 15.8\% من إجمالي المبيدات التي أظهرتها نتائج الدراسة لإجمالي العينات منها نحو 8.3\% أعلى من الحد الأقصى المسموح به وفقا للموصى بها لها عالميا.

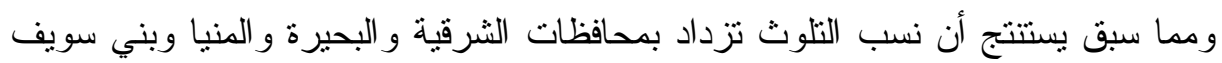
بشكل كبير حيث يتضح ذلك من زيادة نسب العينات الملوثة وزيادة نسب العينات التي تخطت الحد بد بلد الأقصى المسموح به مما يدل إقتصاديا على وجود هدر في استخدام المبيدات وزيادة التكاليف وبالتالي عدم وجود كفاءة اقتصادية في استخدام المورد. كما أنه يوجد قدر كبير من المحصولين يتت فقده على مستوى أسواق العينة. حيث تبين أن مقدار الفقد او الخسارة التى تحدث نتيجة ما تبيقى من

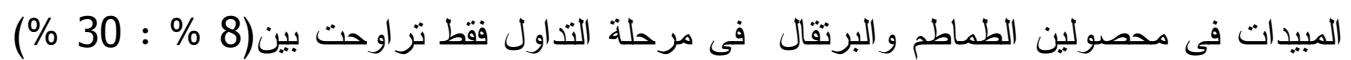

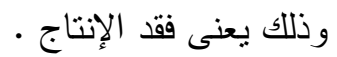




$$
\text { تقصى متبقيات المبيدات فى الطماطم والبرتقال: }
$$

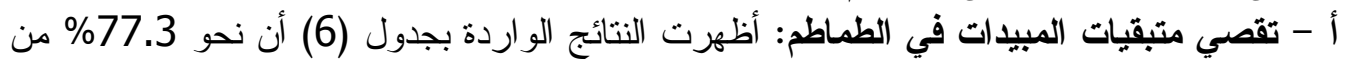

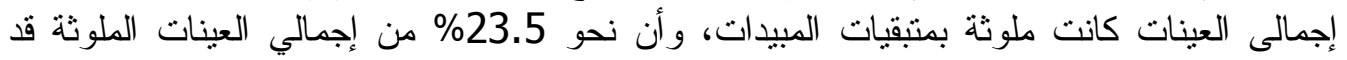

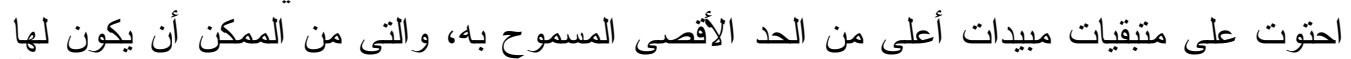

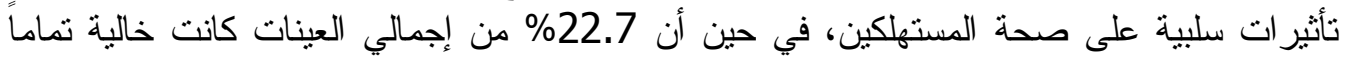

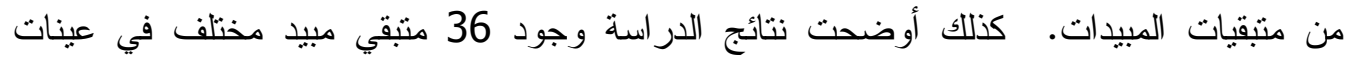

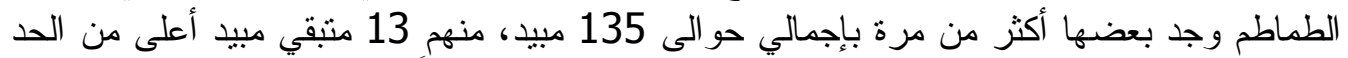

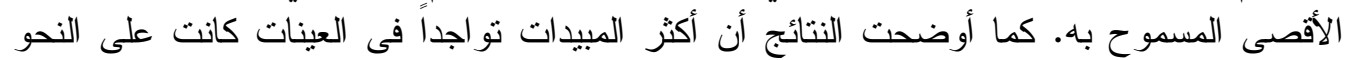

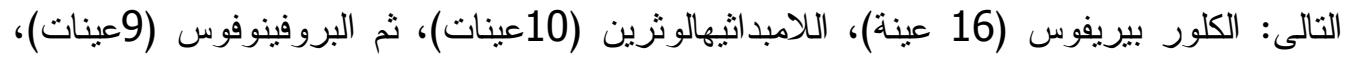

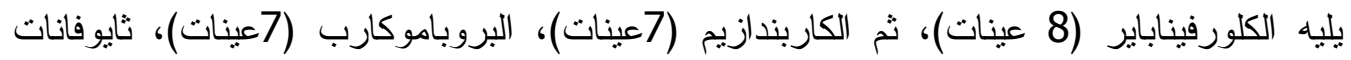

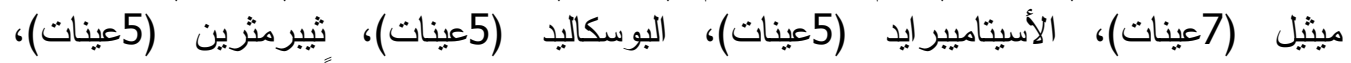

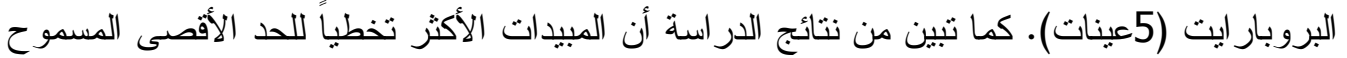

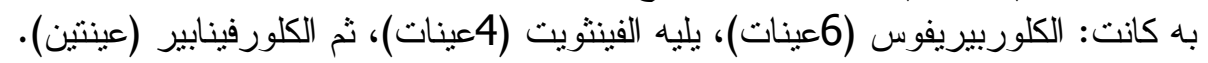

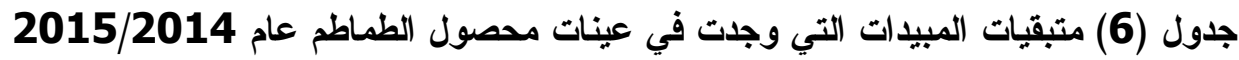

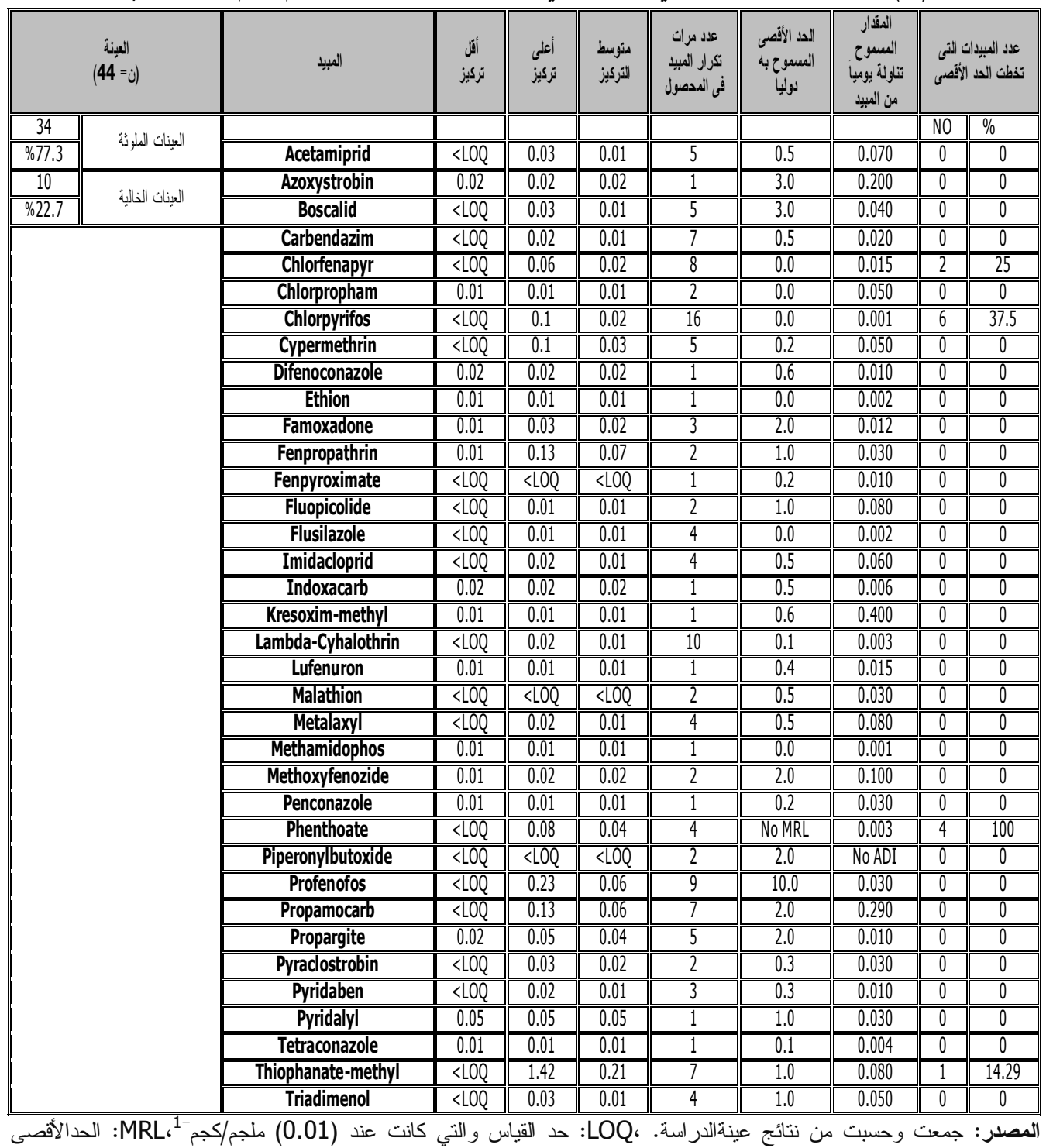

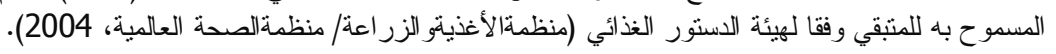


ب - تقصي متبقيات المبيدات في البرتقال: أظهرت النتائج بجدول (7) أن 79.5\% من

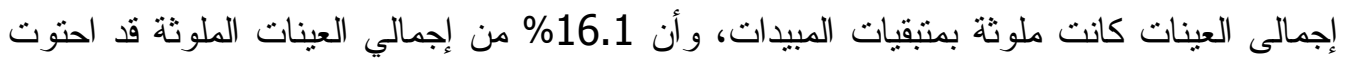

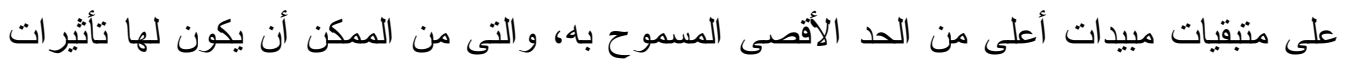

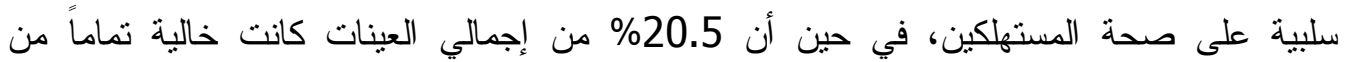

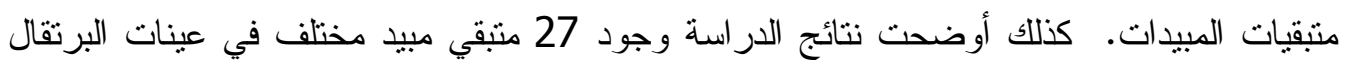

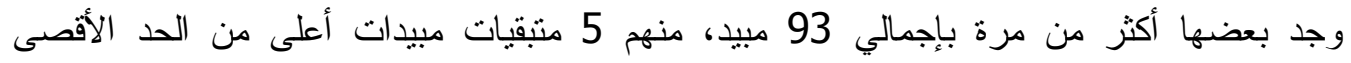

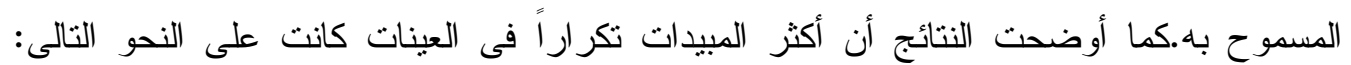

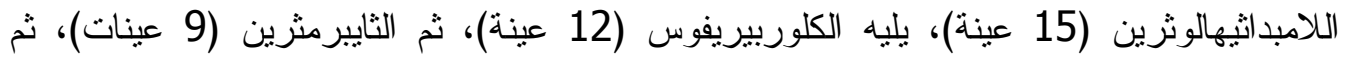
الإيماز اليل (7 عينات)، يليه البروفينوفوس (5 عينات)، ثم الثيابندازول (5 عينات). كما تبين من

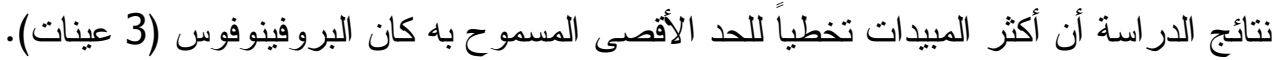

جدول (7) متبقيات المبيات التي وجلت في عينات محصول البرتقال 2015/2014 اليرات

\begin{tabular}{|c|c|c|c|c|c|c|c|c|c|c|}
\hline \multicolumn{2}{|c|}{ (ن) العينة } & \multirow[t]{2}{*}{ 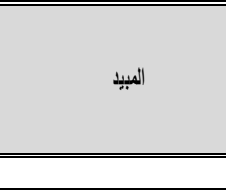 } & \multirow[t]{2}{*}{ أقلى تركيز } & \multirow[t]{2}{*}{ نركيز } & \multirow[t]{2}{*}{ هتركسط } & \multirow[t]{2}{*}{ كرار المبيد } & \multirow[t]{2}{*}{ 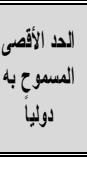 } & \multirow[t]{2}{*}{ تنالمة المسوح } & \multicolumn{2}{|c|}{ تذلد المبيدات التى الدأد } \\
\hline 31 & \multirow{2}{*}{ العينات الملئونة } & & & & & & & & $\overline{\mathrm{NO}}$ & $\%$ \\
\hline \%79.5 & & Acetamiprid & $<\angle O Q Q$ & 0.02 & 0.01 & 3 & 0.0200 & 0.0700 & 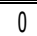 & 0 \\
\hline 8 & \multirow[b]{2}{*}{ العينات الخالية } & Atrazine & 0.02 & 0.02 & 0.02 & $\overline{1}$ & 0.0500 & 0.0200 & $\overline{0}$ & 0 \\
\hline \multirow[t]{25}{*}{$\% 20.5$} & & Carbendazim & $<\angle O Q$ & $\angle \angle O Q$ & $\angle L O Q$ & 1 & 1.0000 & 0.0200 & $\overline{0}$ & 0 \\
\hline & & Chlorpropham & 0.01 & 0.01 & 0.01 & 2 & 0.0100 & 0.0500 & $\overline{0}$ & 0 \\
\hline & & Chlorpyrifos & $\angle \mathrm{LOOQ}$ & 0.05 & 0.017 & $\overline{12}$ & 0.3000 & 0.0010 & 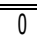 & 0 \\
\hline & & Cyfluthrin & 0.02 & 0.02 & 0.02 & $\overline{11}$ & 0.3000 & 0.0030 & 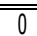 & 0 \\
\hline & & Cypermethrin & 0.01 & 0.05 & 0.026 & $\overline{9}$ & 0.3000 & 0.0500 & 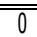 & 0 \\
\hline & & $\begin{array}{l}\text { Diazinon } \\
\end{array}$ & $\angle \angle O Q Q$ & 0.01 & 0.002 & $\overline{\overline{4}}$ & 0.0100 & 0.0002 & $\overline{00}$ & 0 \\
\hline & & $\begin{array}{l}\text { Difenoconazole } \\
\end{array}$ & $\angle \angle O Q$ & 0.01 & 0.005 & 2 & 0.6000 & 0.0100 & 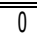 & 0 \\
\hline & & Dimethoate & $\angle \mathrm{LOQ}$ & 0.03 & 0.016 & $\overline{3}$ & 0.0200 & 0.0010 & 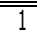 & 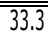 \\
\hline & & Fenpropathrin & 0.01 & 0.01 & 0.01 & 1 & 2.0000 & 0.0300 & 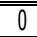 & 0 \\
\hline & & Imazalil & 0.05 & 0.88 & 0.289 & 7 & 5.0000 & 0.0250 & 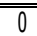 & 0 \\
\hline & & Imidacloprid & 0.01 & 0.01 & 0.01 & 2 & 1.0000 & 0.0600 & 0 & 0 \\
\hline & & Lambda-Cyhalothrin & $\angle L O Q$ & 0.08 & 0.015 & $\overline{15}$ & 0.2000 & 0.0025 & $\overline{0}$ & 0 \\
\hline & & Malathion & 0.01 & 0.02 & 0.013 & 3 & 2.0000 & 0.0300 & 0 & 0 \\
\hline & & Methamidophos & $\angle \mathrm{LOQ}$ & $\overline{\angle L O Q}$ & $\angle \mathrm{LOQ}$ & $\overline{11}$ & 0.0100 & 0.0010 & 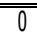 & 0 \\
\hline & & Omethoate & $\angle \angle 0 Q$ & 0.07 & 0.035 & 2 & 0.0200 & 0.0003 & 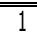 & 250 \\
\hline & & Ortho-Phenyl Phenol (OPP) & 0.08 & 1.22 & 0.503 & 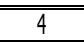 & 10.000 & 0.4000 & 0 & 0 \\
\hline & & Phenthoate & $\angle \mathrm{LOQ}$ & $\angle \angle O Q$ & $\angle L O Q$ & 1 & 0.0200 & 0.0030 & 0 & 0 \\
\hline & & Piperonylbutoxide & $\angle \angle 0 Q$ & 0.05 & 0.023 & 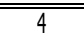 & 5.0000 & $\begin{array}{l}\text { No ADI } \\
\end{array}$ & 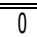 & 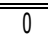 \\
\hline & & Profenofos & 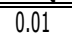 & 0.07 & 0.034 & $\overline{5}$ & 0.0100 & 0.0300 & 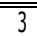 & 260 \\
\hline & & Spinetoram & 0.04 & 0.04 & 0.04 & $\overline{11}$ & 0.0700 & 0.0250 & $\overline{00}$ & $\overline{00}$ \\
\hline & & Spinosad & 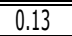 & 0.13 & 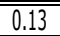 & $\overline{11}$ & 0.3000 & 0.0240 & 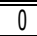 & 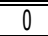 \\
\hline & & Spirodiclofen & 0.01 & 0.01 & 0.01 & $\overline{11}$ & 0.4000 & 0.0150 & $\overline{00}$ & $\overline{0}$ \\
\hline & & $\begin{array}{c}\text { Sulfur } \\
\end{array}$ & 88.2 & 88.2 & 888.2 & $\overline{11}$ & 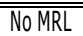 & No ADI & $\overline{0}$ & $\overline{0}$ \\
\hline & & Thiabendazole & $\overline{0.02}$ & 0.22 & $\overline{0.144}$ & $\overline{55}$ & 7.0000 & 0.1000 & $\overline{00}$ & $\overline{00}$ \\
\hline & & 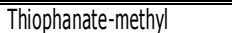 & 0.01 & 0.01 & 0.01 & $\overline{11}$ & 6.0000 & 0.0800 & 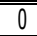 & $\overline{00}$ \\
\hline
\end{tabular}

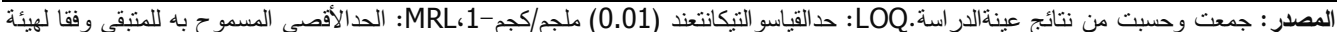
الدستور الغذائي (منظمة الأغذيتو الزئج اعة / منظمة الصحة العالمية، 2004).

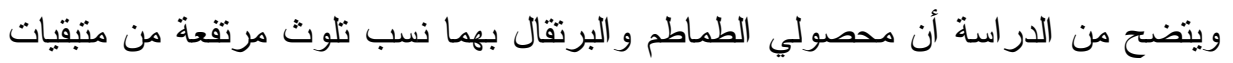

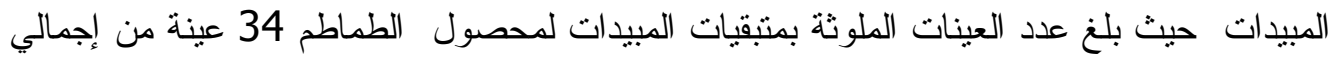
44 عينة بنسبة بلغت 77.3\% في حين بلغت العينات الملوثة بمحصول البرتقال 31 عينة من

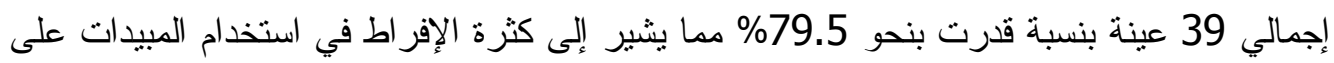

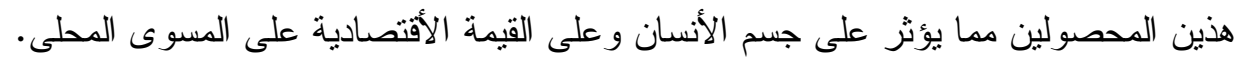


2- تحليل المخاطر الصحية المحتملة والمرتبطة بالتعرض لمتبقيات المبيدات التى تخطت الحد

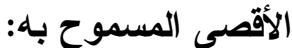

وفى هذه الدراسة تم تحليل المخاطر الصحية الناتجة عن استهلاك الإنسان للغذاء الملوث بمتبقيات المبيدات بكميات تخطت الحدود المسموح بها يومياً وذلك عن طريق حساب مؤشرات الخطر لهذه

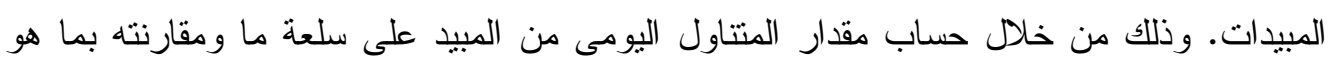
مسموح تتاوله يومياً من ذات المبيد على تلأك السلعة. يتم حساب المتتاول اليومى المحسوب estimated daily intake (EDI) للمبيدات التى دئى تخطت الحد الأقصى المسموح به Maximum Residue Limit (MRL) فى كل محصول عن طريق ضرب منتسط نركيز المبيد فى مقدار المتتاول اليومى من المحصول بالنسبة للمستهلك المصرى بهى

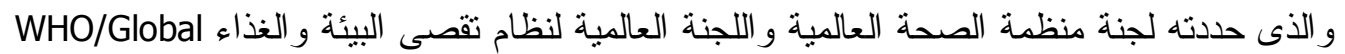
Environment Monitoring System-Food (WHO/GEMS/FOODS, 2006) الغذائي المصرى ضمن الفئة C. و ينم حساب مؤشر الخطر عن طريق قسمة المتتاول اليومى المحسوب لكل مبيد على المقدار المقبول تتاولة بوميا

المبيد و الذى وضعته هيئة سلامة الغذاء الأوروبية European Food Safety Authority (EFSA)

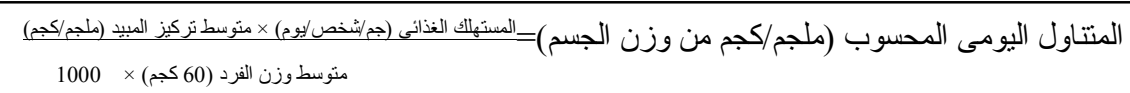

أ- محصول الطماطم: جدول(8) : تنين من نتائج الدر اسة وجود بعض منتقيات المبيدات و التي

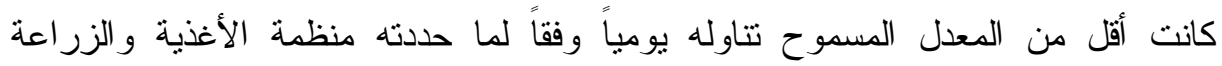
ومنظمة الصحة العالمية، وأن استهلاك تلك الأغذيةالتى تحتوى على المتبقيات المبيدات

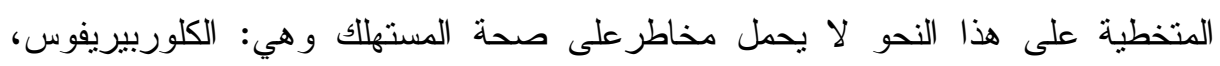
الفينتويت، الثايوفانات ميثيل بمؤشر ات خطورة بلغت نحو ( 3.9\%، 2.17\%، 0.46 \%) من ونس المقدار المقبول تتاوله يومياً على الترتيب.

جدول (8) المتناول اليومى المحسوب للمبيدات التى تخطت الحد الأقصى المسموح به في عينات الطماطم عام 2015/2014

\begin{tabular}{|c|c|c|c|c|c|c|}
\hline المبيد الذى تخطى الحد الأقصى & 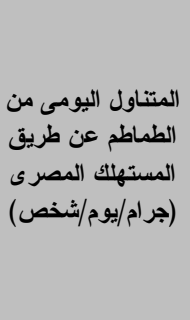 & متوسط & $\begin{array}{c}\text { المحسوب من التناول } \\
\text { المبيد }\end{array}$ & 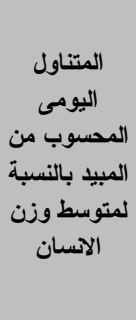 & تناوله يومياً الحسمى الأقصى & 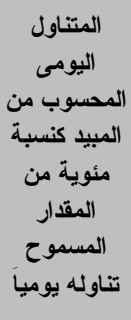 \\
\hline Chlorfenapyr & 102.8 & 0.02 & 1.64 & 0.000027 & 0.015 & 0.18 \\
\hline Chlorpyrifos & 102.8 & 0.02 & 2.36 & 0.000039 & 0.001 & 3.94 \\
\hline Thiophanate-methyl & 102.8 & 0.21 & 21.90 & 0.00036 & 0.08 & 0.46 \\
\hline Phenthoate & 102.8 & 0.04 & 3.91 & 0.000065 & 0.003 & 2.17 \\
\hline
\end{tabular}


ب- محصول البرتقال: جدول(9): توضح نتائج الدراسة لحساب تحليل الدخاطر الصحية المرتبطة بالتعرض لمتبقيات المبيدات التي تخطت الحد الأقصى المسموح به أنها كانت أقل لتصل من المعدل المسموح تتاوله يومياً وفقاً لما حددته منظمة الأغذية و الزر اعة ومنظمة الصحة العالمية، وأن استهلاك ثلاك الأغذية على هذا النحو لا يحمل مخاطر على صحة المستهلك

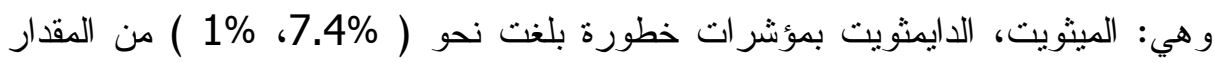
المقبول تتاوله يومياً على التزتيب. و على الرغم من أن النتائج أظهرت أن المخاطر المرتبطة بالتعرض لهنتقيات المبيدات عن طريق المحاصيل الغذائية ضيئلة، إلا أنه يجب اتخاذ محاذير واحتياطات خاصة بالتعرض مستقبلاً للمبيدات عن طريق الأغذية الأخرى المختلفة غير تلك التى شملتها الدراسة، وعليه فإن هذه التقديرات للمتتاول اليومى لا تعتبر تقديرات كلية للمتتاول اليومى حيث إنها لم تشتمل على تقدير

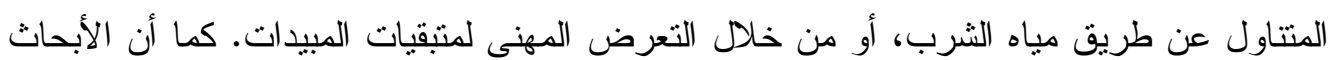
المستقبلية يجب أن تعنى بمعرفة المخاطر الصحية الناتجة عن التعرض التز اكمي للعديد من منتقيات المبيدات، حيث تم حساب ذلك على أساس وجود المبيدات منفرده.

جدول (9) المتناول اليومى المحسوب للمبيدات التى تخطت الحد الأقصى المسموح به في عينات البرتقال عام 2015/2014

\begin{tabular}{|c|c|c|c|c|c|c|}
\hline البيد الأى تنطى الدا لالأصس & 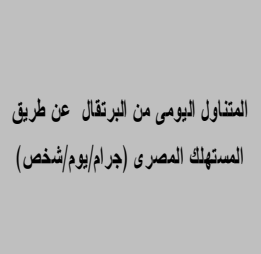 & متوسط نركيز البيد. & المسوب من البيد & 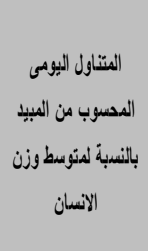 & 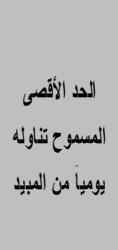 & 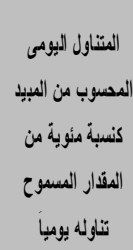 \\
\hline Dimethoate & 38 & 0.02 & 0.6 & 0.00001013 & 0.0010 & 1.01 \\
\hline Omethoate & 38 & 0.04 & 1.3 & 0.00002216 & 0.0003 & 7.39 \\
\hline Profenonós & 38 & 0.03 & 1.3 & 0.0002153 & 0.0300 & 0.07 \\
\hline
\end{tabular}

المصدر : نتائج أستبيان الدراسة.

3- قياس الأثر الإتصادى لإستخدام المبيدات الزراعية لمحصولين الطماطم والبرتقال:

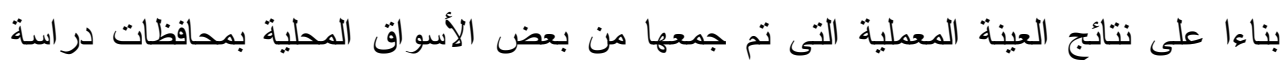

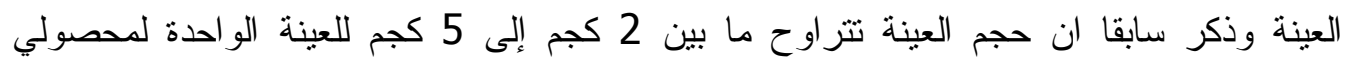

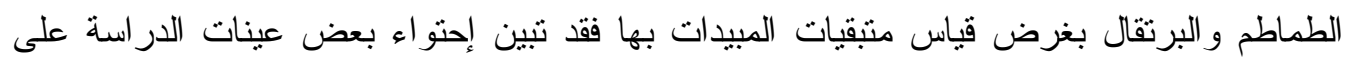

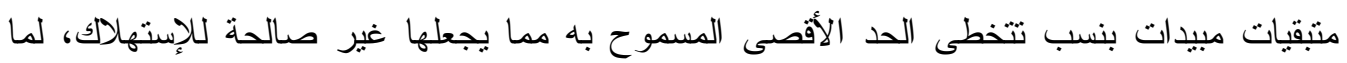
لهامن أثار سلبية سيئة على صحة المستهلك. و هنا يتطلب معرفة مقدار ما يهدر من الإنتاج و الموارد

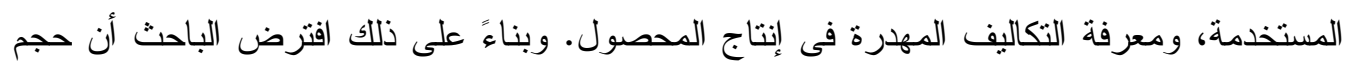

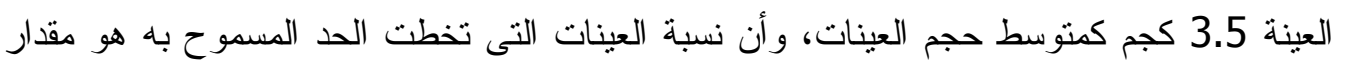
الفاقد من الإنتاج لمحصولي الدراسة (الطماطم، البرتقال) ونبين ذللك على النحو التالي: 
أ- الطماط: يشير الجدول (10) إلى أن إجمالى العينات بمحافظة القليوبية 6 عينات ولم تحتوى على منتقات مبيدات تتخطى الحد المسموح به وبالتالى لا يوجد بها فاقد في الإنتاج

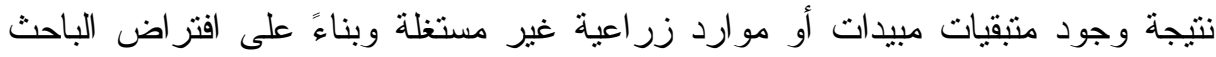
تتسم محافظة القليوبية بالكفاءة الإقتصادية اتجاه ذلك. فى حين أن محافئ رافظة البحيرة كان إجمالى العينات بها 9 عينات ومن نتائج تحليل العينة تنين احتواء 3 عينات على متبقيات مبيدات متخطية الحد المسموح به، تمثل نحو 33\% من إجمالى العينات المحافظة، وبناءً على افتر اض الباحث فتعتبر هذه النسبة هي نسبة الفاقد من الإنتاج نظر اً لعدم صلاحيتها للإستهلاك،، وقدر إنتاج محافظة البحيرة من الطماطم بحو الى 581 ألف طن بمساحة بلغت 36.7 ألف فدان وذلك لعام 2015، وقدر منوسط تكاليف المبيدات ومقاومة الآفات بحو الى 716.7 جنيه /فدان،حيث يتضح أن فاقد الإنتاج يقدر بحو الى 193.5 ألف طن من إنتاج

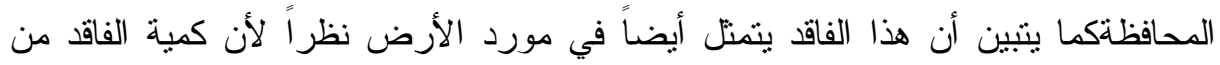
الإنتاج ينت إنتاجها من مساحة تقدر بحو الي 12 ألف فدان وبمتوسط تكلفة مبيدات ومقاومة آفات بلغت نحو 239 جنيه/فدان مما يوضح أن هذه المساحة لم يتم استغلالاها بكفاءة

$$
\text { وبالتالي هدر مورد من موارد الإنتاج. }
$$

جدول (10) الأثر الاقتصادى لإستخدام المبيدات الزر اعية لعينة الاردة لإسة لمحصول

\section{5/2014 الطماطم لموسم}

\begin{tabular}{|c|c|c|c|c|c|c|c|c|c|c|c|c|}
\hline \multicolumn{2}{|c|}{$\begin{array}{c}\text { الجمبيدات } \\
\text { (135 } \\
\end{array}$} & \multirow{2}{*}{ لم أستغلاحة } & \multirow{2}{*}{ اللفاليف } & \multirow{2}{*}{ ألمدفقود } & \multicolumn{2}{|c|}{ 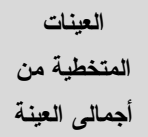 } & \multirow{2}{*}{ | } & \multirow{2}{*}{ |الأنتاج } & \multirow{2}{*}{ (طن/فانان) } & \multirow{2}{*}{ فالفان) } & \multirow{2}{*}{$\begin{array}{l}\text { العينات } \\
=0 \\
(\mathbf{4 4}\end{array}$} & \multirow{2}{*}{ المحافظة } \\
\hline$\%$ & العدد & & & & $\%$ & العدد & & & & & & \\
\hline 19.3 & 26 & - & - & 0 & 0 & 0 & 716.7 & 21.7 & 13.8 & 1.57 & 6 & القليوبية \\
\hline 20.7 & 28 & 12.2 & 239 & 193.5 & 33.3 & 3 & 716.7 & 581 & 15.9 & 36.7 & 9 & البحيرة \\
\hline 15.6 & 21 & 21.5 & 287 & 347.6 & 40 & 2 & 716.7 & 869 & 16.2 & 53.8 & 5 & الثرقية \\
\hline 11.9 & 16 & 2.4 & 102 & 39.7 & 14.3 & 1 & 716.7 & 278 & 16.6 & 16.7 & 7 & سويف \\
\hline 11.1 & 15 & 1.8 & 71.7 & 32.0 & 10 & 1 & 716.7 & 320 & 17.8 & 18.0 & 10 & المنيا \\
\hline
\end{tabular}

المصدر: - وزارة الزر اعة واستصلاح الأراضي -قطاع الشئون الاقتصادية -الإدارة المركزية للاقتصاد الزر اعي والإحصاء- نشرة الاقتصاد

الزر اعي ،2015.

نتائج عينة الدراسة.

أما محافظة الثرقية فبلغ إجمالى العينات بها 5 عينات وتنين من نتائج الدراسة احتواء 2 عينة على متبقيات مبيدات متخطية الحد المسموح به ، تمنل نحو 40\% من إجمالى العينات

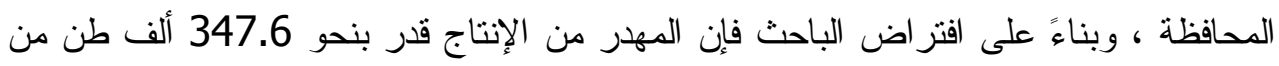

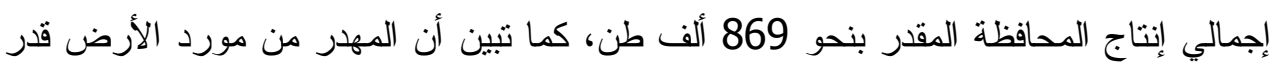

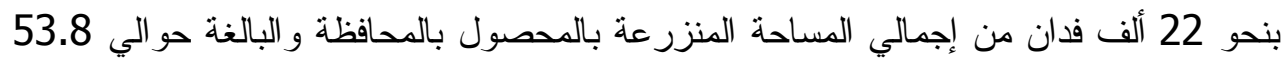


ألف فدان، بمنوسط تكلفة مبيدات ومقاومة آفات بلغت حوالي 287 جنيه/فدان من متوسط تكاليف المبيدات ومقاومة الآفات المقدرة ببحو الى 716.7 جنية /فدان. فى حين أن محافظة بني سويف كان إجمالى العينات بها 7 عينات ومن نتائج تحليل العينة

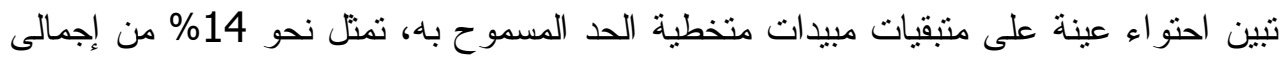

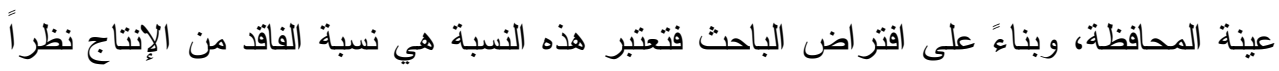

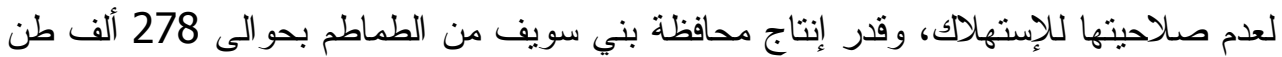
بمساحة بلغت 16.7 ألف فدان، وقدر منوسط تكاليف المبيدات ومقاومة الآفات بحو الى 716.7 جنيه /فدان، حيث يتضح أن فاقد الإنتاج يقدر بحوالى 39.7 ألف طن من إنتاج المحافظة كما ينبين أن هذا الفاقد يتمتل أيضاً في مورد الأرض نظراً لأن كمية الفاقد من الإنتاج يتم إنتاجها من مساحة تقدر بحو الي 2 ألف فدان وبمتوسط تكلفة مبيدات ومقاومة آفات بلغت نحو 102 جنيه/فذان مما يوضح أن هذه المساحة لم ينم استغلالها بكفاءة وبالتالي هدر مورد من موارد

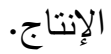

و أخيرًا محافظة المنيا كان إجمالى العينات بها 10 عينات ومن نتائج تحليل العينة تبين احتو اء عينة على متبقيات مبيدات متخطية الحد المسموح به، تمثل نحو 10\% من إجمالى عينة

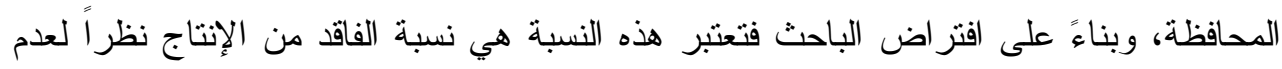

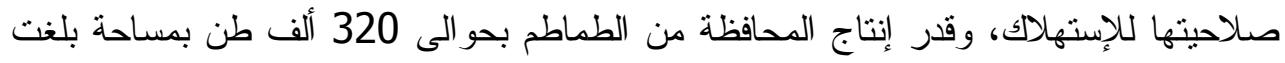
18 ألف فدان، وقدر متوسط تكاليف المبيدات ومقاومة الآفات بحو الى 716.7 جنيه /فدان، حيث يتضح أن فاقد الإنتاج يقدر بحو الى 32 ألف طن من إنتاج المحافظة كما يتبين أن هذا

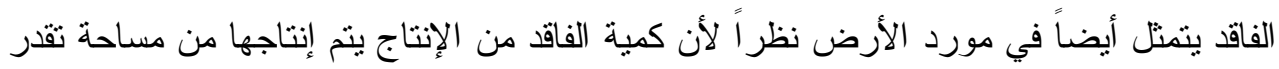

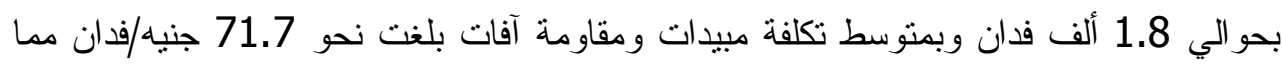
يوضح أن هذه المساحة لم يتم استغلالها بكفاءة وبالنالي هدر مورد من موارد الإنتاج. كما يشير إلى وجود 135 نوع مبيد فى عينات محصول الطماطم إلى إلأسراف في إستخدام

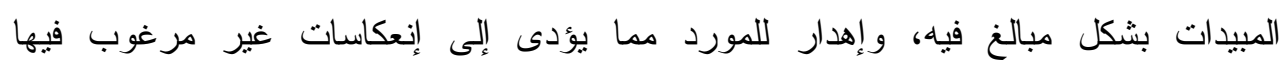
إقتصادياو أجنماعيا.

ب- البرتقال: يشير الجدول (11) إلى أن إجمالى العينات بمحافظة القليوبية 6 عينات ومن

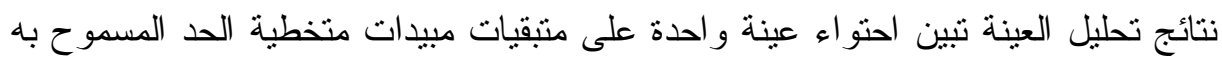

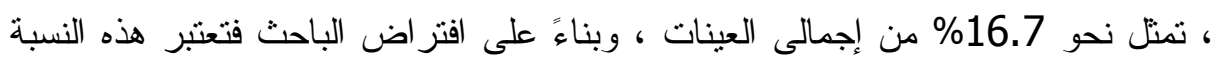

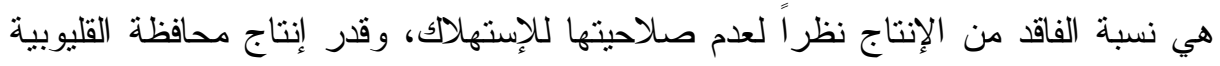
من البرنقال بحو الى 367 ألف طن بمساحة بلغت 32.9 ألف فدان، وقدر منوسط تكاليف المبيدات ومقاومة الآفات بحو الى 3188 جنيه /فدان، حيث يتضح أن فاقد الإنتاج يقدر بحو الى 61 ألف طن من إنتاج المحافظة كما يتبين أن هذا الفاقد يتمثل أيضاً في مورد الإنها الأرض نظراً لأن كمية الفاقد من الإنتاج يتم إنتاجها من مساحة نقدر بحوالي 5.5 ألف الف 
فدان وبمتوسط تكلفة مبيدات ومقاومة آفات بلغت نحو 532 جنيه/فدان مما يوضح أن هذه

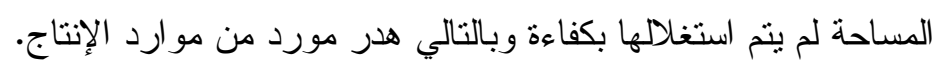

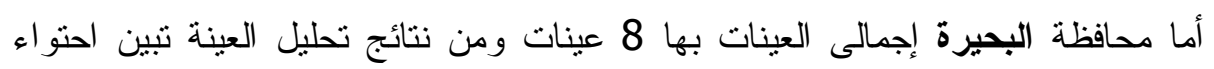
عينة على متبقيات مبيدات متخطية الحد المسموح به ، تمثل نحو 12.5\% من إجمالى العينات ا، وبناءً على افتز اض الباحث فتعتبر هذه النسبة هي نسبة الفاقد من الإنتاج نظر أ لعدم صلاحيتها

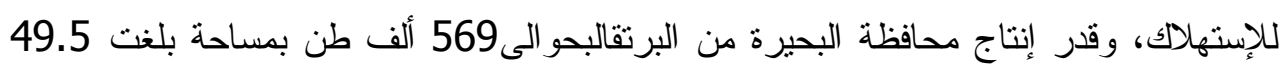

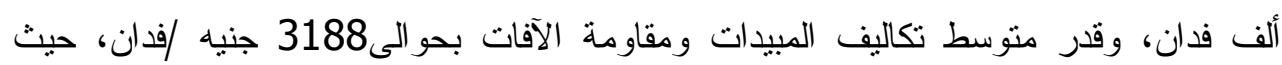
يتضح أن فاقد الإنتاج يقدر بحو الى 71 ألف طن من إنتاج المحافظة كما يتبين أن هذا الفاقد يتمثل

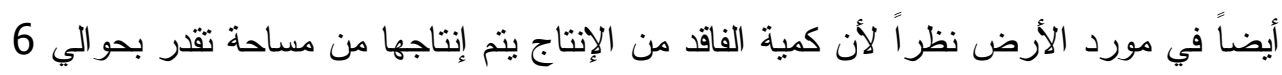

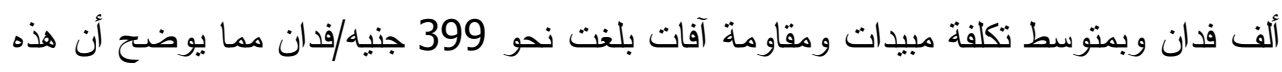
المساحة لم ينم استغلالها بكفاءة وبالتالي هدر مورد من مو ارد الإنتاج.

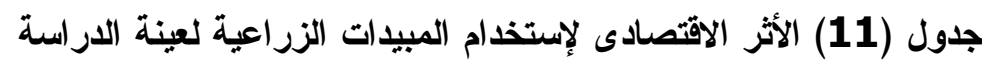

\section{5/2014 لمحصول البرتقال لموسم}

\begin{tabular}{|c|c|c|c|c|c|c|c|c|c|c|c|c|}
\hline \multicolumn{2}{|c|}{$\begin{array}{c}\text { الجبيدات (ن) } \\
\text { (93 } \\
\text { (الجمالي }\end{array}$} & \multirow{2}{*}{ لم أستغلاحنة } & \multirow{2}{*}{ تلكاليف } & \multirow{2}{*}{ المفقتود } & \multicolumn{2}{|c|}{ المتخطية من العينات } & \multirow{2}{*}{ متكال } & \multirow{2}{*}{ (الإتاج } & \multirow{2}{*}{ (طن/فانان) } & \multirow{2}{*}{ (ألف } & \multirow{2}{*}{$\begin{array}{l}\text { العينات } \\
=0 \\
\text { (39 }\end{array}$} & \multirow{2}{*}{ المحافظة } \\
\hline$\%$ & العدد & & & & $\%$ & العدد & & & & & & \\
\hline 12.9 & 12 & 5.5 & 532.4 & 61.2 & 16.7 & 1 & 3188 & 367 & 11.2 & 32.9 & 6 & القليوبية \\
\hline 17.2 & 16 & 6 & 399 & 71.1 & 12.5 & 1 & 3188 & 569 & 11.5 & 49.5 & 8 & البحيرة \\
\hline 21.5 & 20 & 8 & 638 & 66.5 & 20.0 & 1 & 3188 & 332 & 8.8 & 37.7 & 5 & الثرقية \\
\hline 7.5 & 7 & 0 & 0 & 0.0 & 0.0 & 0 & 3188 & 2 & 8.7 & 2.8 & 4 & سويف \\
\hline 22.6 & 21 & 0.2 & 637.6 & 1.2 & 20.0 & 2 & 3188 & 6 & 6.5 & 0.9 & 10 & المنيا \\
\hline
\end{tabular}

المصدر: - وزارة الزراعة واستصلاح الأراضي -فطاع الشئون الاقتصادية -الإدارة المركزية للاقتصاد الزراعي والإحصاء- نشرة الاقتصاد

الزر اعي ،2015.

نتائج عينة الدر اسة.

أما محافظة الثرقية فبلغ إجمالى العينات بها 5 عينات وتبين من نتائج الدراسة احتو اءعينة على ماتى متبقيات مبيدات متخطية الحد المسموح به ، تمثل نحو 20\% من إجمالى العينات ، وبناءً على فئى افتر اض الباحث فإن المهدر من الإنتاج قدر بنحو 66.5 ألف طن من إجمالي إنتاج المحافظة المقدر بنحو 332 ألف طن، كما تبين أن المهدر من مورد الأرض قدر بنحو 8 ألف فئن فدان من إجمالي المساحة المنزرعة بالمحصول بالمحافظة والبالغة حوالي 37.7 ألف فدان، بمنتوسط نكلفة مبيدات 
ومقاومة آفات بلغت حوالي 638 جنيه/فدان من منوسط تكاليف المبيدات ومقاومة الآفات

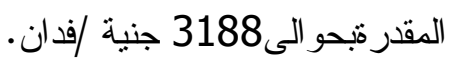

أما محافظة بنى سويف منها 4 عينات ولم تحتوى على متبقات مبيدات تتخطى الحد المسموح به وبالتالى لا يوجد بها فاقد في الإنتاج نتيجة وجود متنقيات مبيدات أو موارد زر اعية غير منات مستغلة

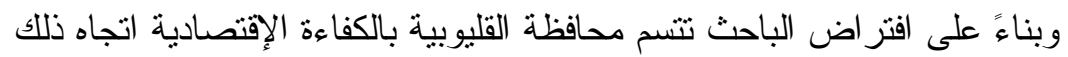
و أخيراً محافظة المنيا كان إجمالى العينات بها 10 عينات ومن نتائج تحليل العينة نبين احتواء 2 عينة على متبقيات مبيدات متخطية الحد المسموح به، تمنل نحو 20\% من إجمالى عينة المحافظة، وقدر إنتاج المحافظة من البرتقال بحو الى 6 ألف طن بمساحة بلغت 0.9 ألف فدان، وقدر متوسط بـانه

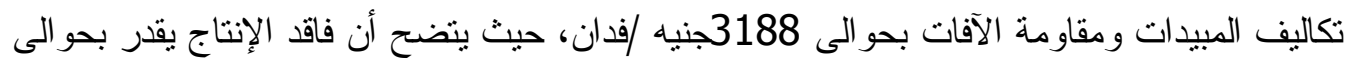

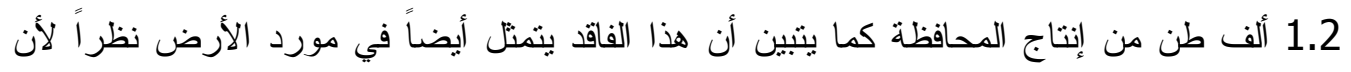

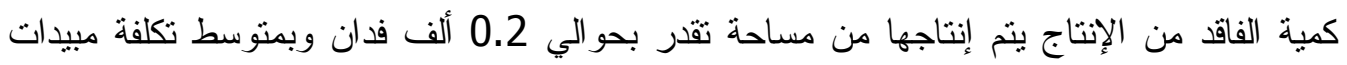
ومقاومة آفات بلغت نحو 637.6 جنيه/فدان مما يوضح أن هذه المساحة لم يتم استغلالها بكفاءة وبالتالي هدر مورد من موارد الإنتاج. ومما سبق يتبين أن محافظة الشرقية من أكثر المحافظات تفقد إنتاج لكلا المحصولين الطماطم و البرتقال حيث بلغ كمية الإنتاج المفقود حوالى 347.6 ، 66.5 ألف طن على الترتيب. وتنفق

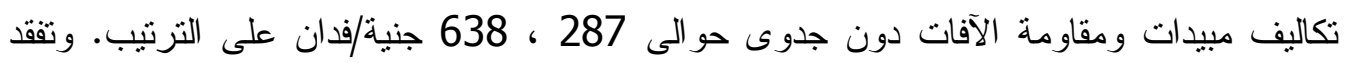

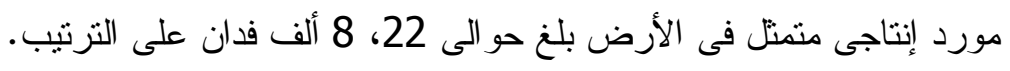

\section{الملخص}

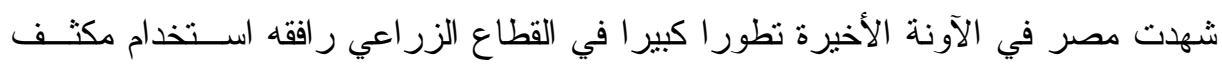

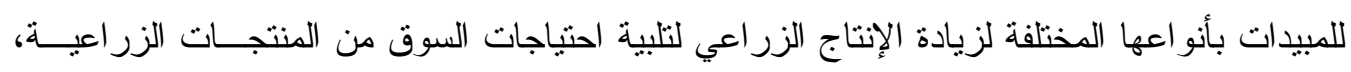

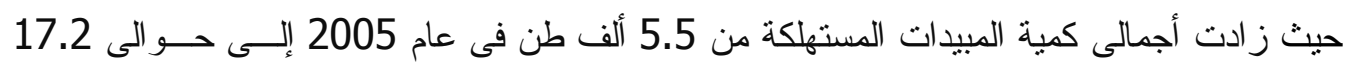

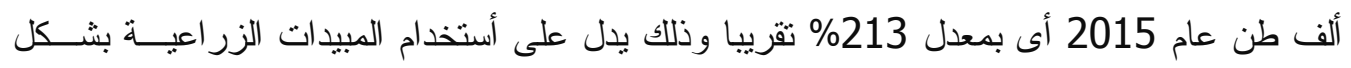
مكنف خلال العشر سنوات الأخيرة. ويعتبر البرتقال و الطماطم من أهم الهحاصيل إنتاجا وأستهلاكا وتصدير ا فى مصر علاوة على ذلك فأن المحصولين أكثر قبو لا لذوق المستهلك المصرى، حيث بلغ إنتاج البرتقال عام 2015 حو الى 3.3 مليون طن و الإستهلاك منه 2 مليون طن فى حين بلغ كمية الصادرات حو الى 1.3

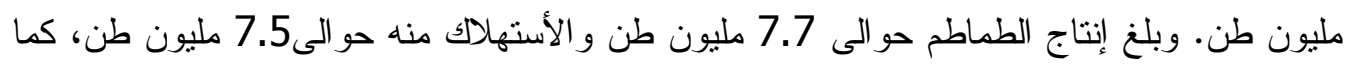

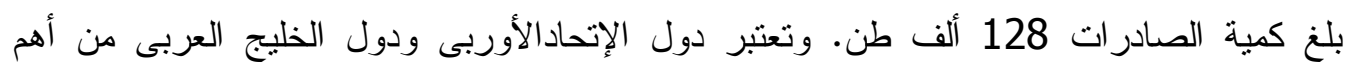
الأسواق التى تستوعب صادر اتتا المصرية .وتضع هذه الأسواق شروطا صارمة على ونى واردنها،

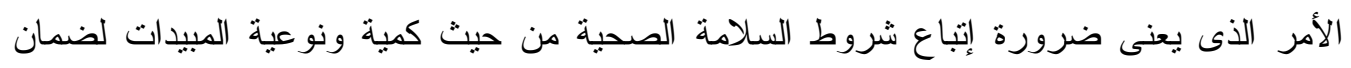
النفاذية المستمرة لهذه الأسو اق الخارجية.

وتكمن مشكلة الدراسة فى مواجهة بعض الصادرات المصرية لكثير من الثروط البيئية و الصحية التى تحد من كمية نفاذها الأسواق الخارجية. وبالر غم من تز ايد الوعى الصحي و البيئي 
بخطورة المبيدات فى الإنتاج ألا إنها ماز الت تستخدم بشكل مفرط وغير أمن فى الزر اعة المصرية بشكل عام. ولذلك تكمن المشكلة فى الإنعكاسات السلبية لأستخدامها. وفى ضوء المشكلة يهدف البحث إلى التعرف على الأهمية الأقتصادية لمحصولى الطماطر

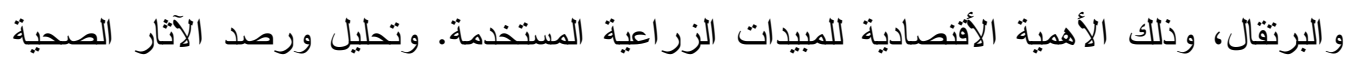
على المستهلكين لإستخدام المبيدات الزر اعية لعينة من محصولى الار اسة.

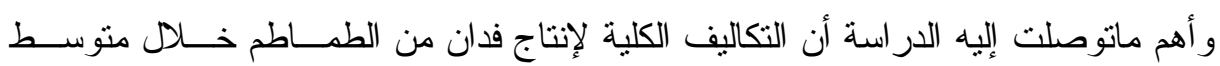

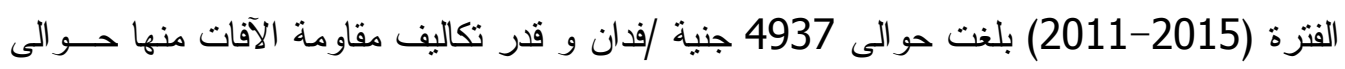
376 جنبة/فدان تمثل نحو 7.6\% من أجمالى التكاليف ، وقدر قيمة المبيدات المستخدم حوالى 233

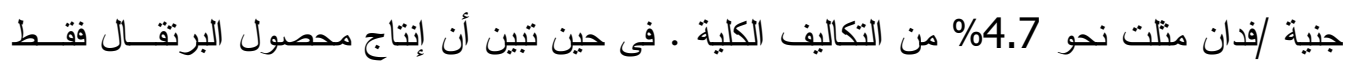
يمنل حو الى 72\% من أجمالى إنتاج الموالح لذلك سوف نشير إلى نكاليف المو الح لعدم نو افر تكاليف

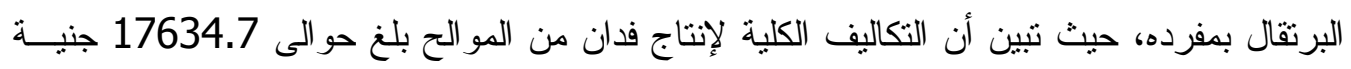

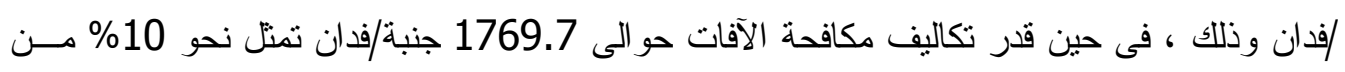

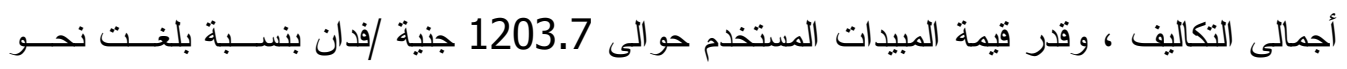

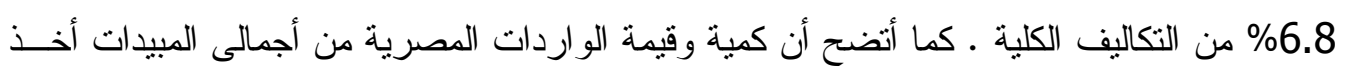

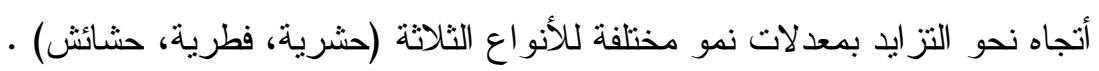

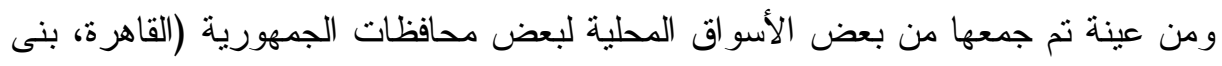

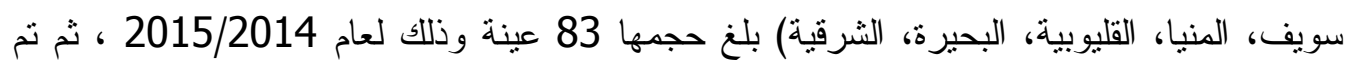
أختيار بعض التجار بصورة عثو ائية، ومن كل تاجر عينة من عدة أماكن عشو ائيا، تتز اوح حجم كل عينة من( 2 كجم إلى 5 كجم) ، ثم بعد ذلك يتم خلط العينة الواحدة وياخذ منها عينة ممثلة ليتم تحليلها داخل المعمل.. حيث كانت عدد عينات محصول الطماطم 44، البرتقال 39 عينة. وأستنتج أن عدد العينات الخالية من متبقيات المبيدات 18 عينة تمثل 21.7\% من إجمالى العينات، وبلغ عدد العينات الملوثة بمتبقيات المبيدات 65 عينة تمنل 78.3\% من إجمالى العينات، وكان عدد العينات التى تخطت الحد الأقصى المسموح به من منبقيات المبيد 13 عينة بنسبة 20\% من عن إجمالى العينات الملوثة بمتبقيات المبيدات والتى من الممكن أن يكون لها تأثثر ات سلبية على صحة المستهاتكين.

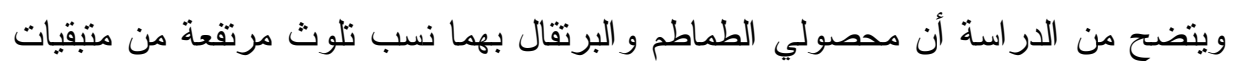

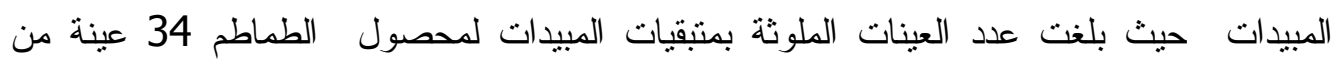
إجمالي 44 عينة بنسبة بلغت 77.3\% في حين بلغت العينات الملوثة بمحصول البرتقال 31 عينة من إجمالي 39 عينة بنسبة قدرت بنحو 79.5\% مما يشير إلى كثرة الإقر اط في استخدام المبيدات على هذين المحصولين.

وتم تحليل المخاطر الصحية الناتجة عن استهلاك الإنسان للغذاء الملوث بمتبقيات المبيدات وأظهرت النتائج أن المخاطر المرتبطة بالتعرض لمتبقيات المبيدات عن طريق المحاصيل الغذائية ضيئلة، إلا أنه يجب اتخاذ محاذير واحتياطات خاصة بالتعرض مستقبلاً للمبيدات عن طريق طن الأغذية

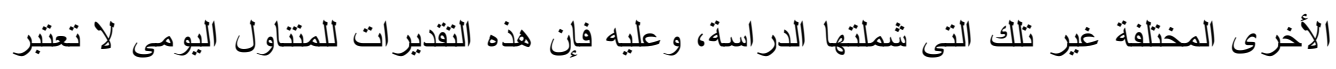




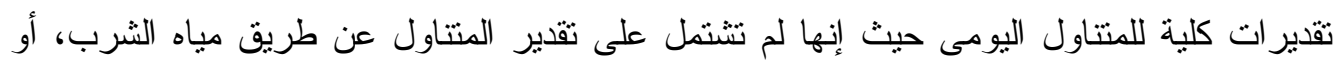

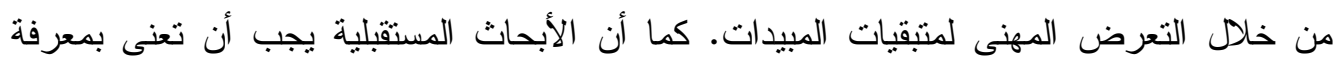
المخاطر الصحية الناتجة عن التعرض التراكي للعديد من متبقيات المبيدات، حيث تم حساب ذلك لكابن على أساس وجود المبيدات منفرده. و أنضح أن نسب التلوث تزداد بمحافظات الثرقية و البحيرة و المنيا وبني سويف بشكل كبير

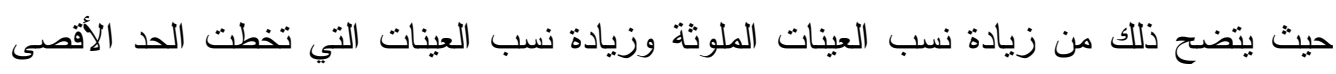

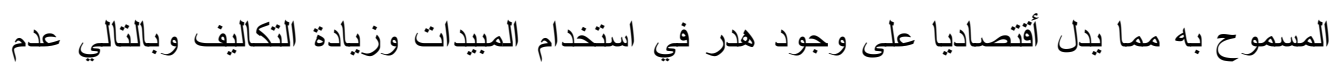

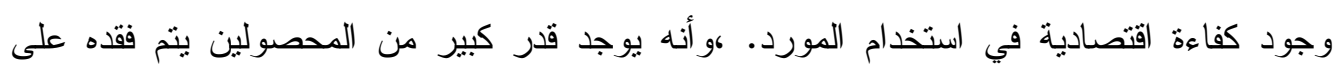
مستوى أسواق العينة. حيث تبين أن مقدار الفقد او الخسارة التى تحدث نتيجة ما تنبقى من المبيدات

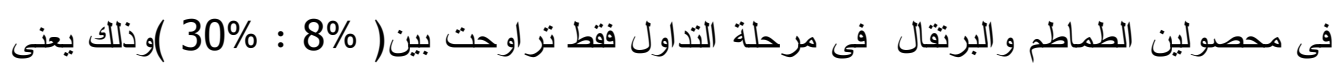

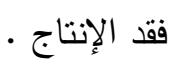

وينبين أن محافظة الشرقية من أكثر المحافظات تفقد إنتاج لكلا المحصولين الطماطم

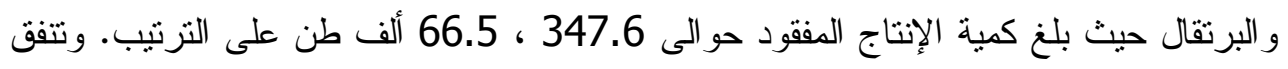
تكاليف مبيدات ومقاومة الآفات دون جدوى حو الى 287 ، 638 جنية/فدان على الترنيب.

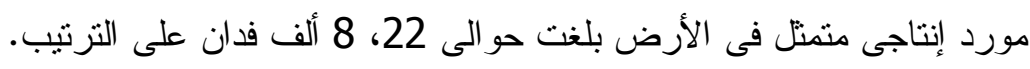

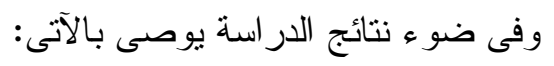

1- زيادة الأهتمام بالتوعية و التدريب للمز ارعين على ترشيد استخدام المبيدات وطرق تطبيقها المتلى لتقليل التلوث بها.

2- استمر ار برامج التقصى لمتبقيات المبيدات فى كل المنتجات الغذائية لتوفير وتحديث قاعدة

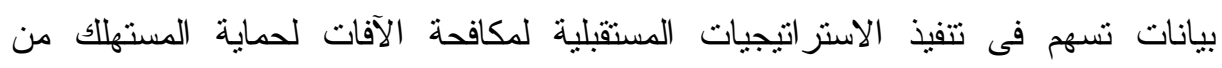
التعرض العشو ائى للمبيدات المستخدمة.

3- وضع قو انين تساعد على تشديد العقوبات على الثركات المصدرة التي يتم رفض شحناتها

لوجود متبقيات مبيدات بها وعدم السماح بتداول منتجاتها بالأسو اق المحلية.

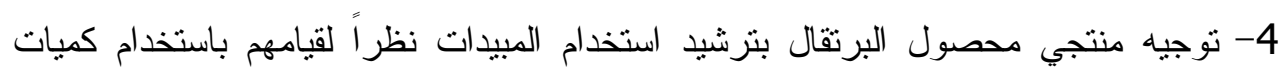
كبيرة من المبيدات يترتب عليه حدوث تلوث للمحصول وبالتالي حدوث خسائر اقتصادية

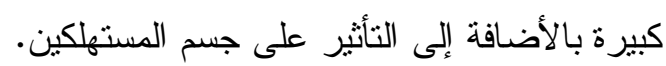

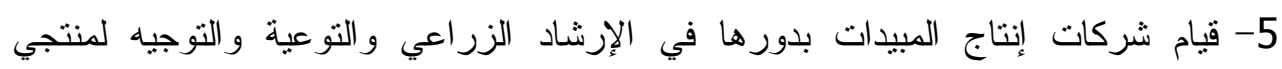

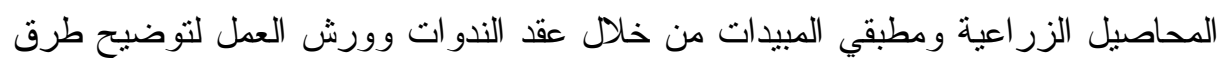
الإستخدام الأمتل للمبيدات وأفضل طرق تطبيقها على المحاصيل للوصول إلى النتائج 


\section{المراجع}

\section{أولاً: مر اجع باللغة العربية:}

1- الجهاز المركزي للتعبئة العامة والإحصاء، شبكة مركز المعلومات (www.capmas.gov.eg).

2- السيد حسن جادو ، السيد عبد العظيم الخشن (دكتور) ، الآثار الأقتصادية والبيئية لإستخدام

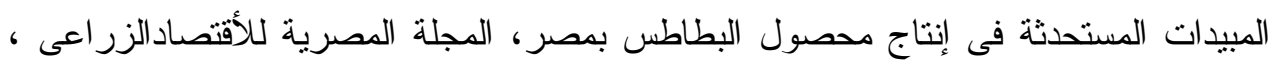

المجلد الر ابع و العشرون ، العدد الثالث، سبتمبر 2014.

3- إلهام إبراهيم يونس ، هالة محمد نور الدين (دكتور) ،الآثار الاقتصادية والبيئية لإستخدام

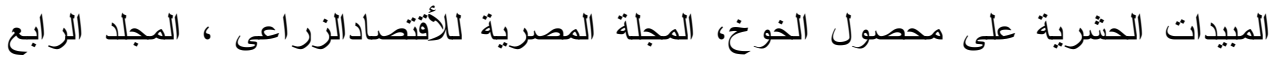

$$
\text { و العشرون ، العدد الر ابع، ديسمبر } 2014 .
$$

4- سهرة خليل عطا ، محمد محمود نور الدين (دكتور) ، الثقييم الاقتصادى للمكافحة المتكاملة،

المجلة المصرية للأقتصادالزر اعى، المجلد السادس و العشرون، العدد الثانى، يونيو 2016.

5- كتاب التوصيات المعتمدة لمكافحة الآفات الزر اعية، لجنة مبيدات الآفات الزر اعية ، 2015.

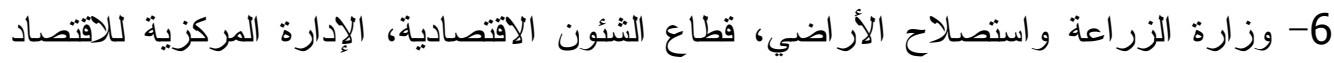

$$
\text { الزر اعي و الإحصاء، لجنة مبيدات الآفات الزر اعية، أعداد منقرقة. }
$$

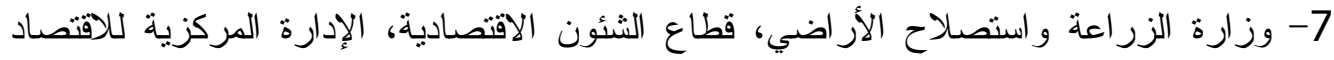

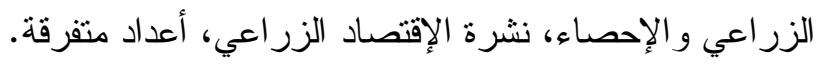

8- وزارة الزراعة و استصلاح الأراضي ، مركز البحوث الزر اعية، المعدل المركزي لتحليل

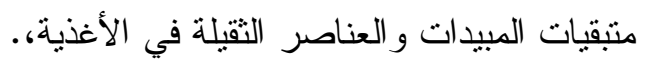

9- Anastassiades, M., Lehotay, S.J., Štajnbaher, D, Schenck, F.J., (2003). Fast and easy multiresidue method employing acetonitrile extraction/partitioning and "dispersive solidphase extraction" for the determination of pesticide residues in produce. J. AOAC Int., 86: 412-431.

10- Banerjee, K., Mujawar, S., Utture, S.C., Dasgupta, S., Adsule, P.G., (2013). Optimization of gas chromatography-single quadrupole mass spectrometry conditions for multiresidue analysis of pesticides in grapes in compliance to EUMRLs. Food Chemistry, 138: 600-607.

11- Chen, C., Qian, Y., Chen, Q., Tao, C., Li, C., Li, Y., (2011). Evaluation of pesticide residues in fruits and vegetables from Xiamen, China. Food Control, 22:11141120.

12- European Commission, (2010). EU Pesticides database. Available from: $<$ http://ec.europa.eu/sanco_pesticides/public/index.cfm.<

13- ec.europa.eu/food/safety/rasff/portal en 
14- FAO/WHO (Food and Agriculture Organization/World Health Organization), (2004). Food standards programme, Codex Alimentarius Commission, Twentyseventh Session, Geneva, Switzerland, 28 June - 03 July 2004.

15- FAO/WHO, (2008). Dietary exposure assessment of chemicals in food. Report of a joint FAO/WHO consultation, Annapolis, Maryland, USA, 2-6 May 2005.

16- F.I. Eissa1, A.A. Helalia, M.A. Khorshid, M.A. El-Sisi, Monitoring of multi-class pesticide residues in green grape and their potential risk for Egyptian consumers,Nature and Science 2013; www.sciencepub.net/nature/ns.

17- Mahmoud El-sisi,"Studies on risk analysis of some organ phosphorus pesticides in food", M.Sc Dissertation, Department of Environment and Bio-Agriculture, Faculty of Agriculture, Al-Azhar University, 2014.

18- WHO, (1997). Guidelines for predicting dietary intake of pesticide residues (revised) global environment monitoring system - food contamination monitoring and assessment programme (GEMS/Food) in collaboration with Codex Committee on pesticide residues. Programme of Food Safety and Food Aid, pp. 1-44.

19- WHO/GEMS/FOODS (2006). WHO/Global Environment Monitoring System-Food Contamination Monitoring and Assessment Program. Consumption cluster diets. <http://www.who.int/foodsafety/chem/gems/en/>. 